\title{
A Review on the Selected Applications of Battery-Supercapacitor Hybrid Energy Storage Systems for Microgrids
}

\author{
Muhammad Khalid 1,2 (D) \\ 1 Electrical Engineering Department, King Fahd University of Petroleum and Minerals, Dhahran 31261, \\ Saudi Arabia; mkhalid@kfupm.edu.sa; Tel.: +966-13-860-8076 \\ 2 K·A.CARE Energy Research \& Innovation Center, Dhahran 31261, Saudi Arabia
}

Received: 23 October 2019; Accepted: 20 November 2019; Published: 29 November 2019

\begin{abstract}
This paper presents a comprehensive categorical review of the recent advances and past research development of the hybrid storage paradigm over the last two decades. The main intent of the study is to provide an application-focused survey where every category and sub-category herein is thoroughly and independently investigated. Implementation of energy storage systems is one of the most interestingly effective options for further progression in the field of alternative energy technology. Apart from a meticulous garnering of the energy resources regulated by the energy storage, the main concern is to optimize the characteristic integrity of the storage devices to achieve a practically techno-economic size and operation. In this paper, hybrid energy storage consisting of batteries and supercapacitors is studied. The fact that the characteristic of batteries is mostly complementary to that of supercapacitors, hybridizing these storage systems enhances their scope of application in various fields. Therefore, the objective of this paper is to present an inclusive review of these applications. Specifically, the application domain includes: (1) regulation of renewable energy sources, (2) contributions to grid regulation (voltage and frequency compensation, contribution to power system inertia), (3) energy storage enhancements (life cycle improvement, and size reduction), (4) regenerative braking in electric vehicles, (5) improvement in wireless power transfer technology. Further, this review also descriptively highlights the control strategies implemented in these domains of applications. The application-oriented review explicates the principle advantages with the hybridization of battery and supercapacitor energy storage systems that can be used as an insight for further development in the field of energy storage technology and its applications.
\end{abstract}

Keywords: battery; electric vehicles; hybrid energy storage systems; power quality; renewable energy sources; supercapacitors; renewable generation

\section{Introduction}

The application of batteries has come a long way since its inception, ranging from commercial electronic equipment, satellite applications, medical instrumentation, substation installation to the electrical circuitry of conventional vehicles. Conventionally, the principle of application of batteries was based on its capability to allow devices to be electrically autonomous. Further, with the introduction of green revolution owing to the rapid growth due ever-increasing energy consumption, increment in population and urbanization, the battery technology concurrently matured with it, paving its way and, hence establishing its prominence in power sector.

Considering the objective of reducing greenhouse emission and heed to the global demand-supply mismatch, that is, to optimize energy usage and minimize fuel consumption and toxic emissions. Among various alternatives to fossil fuels, renewable energy sources (RES) and electric vehicles (EV) 
are some of the most researched and matured technological propositions. Energy storage systems (ESS), being multifaceted in their applications, form the foundation for technological advancement in RES and EV. In this field, several excellent discoveries and proposition have been made for the applications of batteries for RES output power stabilization, wireless RES power transfer, peak-shifting, electricity market pricing and scheduling, grid voltage and frequency regulations, increasing RES penetration with inertial contribution to the grid, peak clipping-valley filling due to RES integration in the main grid [1-4], and further commercialization of EVs with enhanced driving and acceleration range with increased performance of due to recuperation of regenerative braking [5-7].

Even though batteries can aptly perform in these applications, batteries possess certain inconvenient characteristics such as low power density, limited life cycle and comparatively slow response in terms of the requirements of the applications. This might limit the feasibility of battery when dealing with transient high-power demands, such as the transient RES output power and load variability leading to an oversized design of batteries with increased investment cost and an additional power loss owing to the slow response of the batteries to compensate for transient peak power demands.

Moreover, the majority of electronic devices, EVs and telecommunication system possess a common load profile, described by the relatively high peak-to-peak average power requirement. These kinds of loads can be closely represented as a constant current characteristic, that is a pulsed load profile, hence, sulphating batteries in robust and standalone operations due to the high current profile leading to increased system losses and constant need for battery replacement. Supercapacitors, also known as electric double layer capacitors, have 20 times more energy storage capacity than conventional electrolytic capacitors and in contrast to batteries, supercapacitors can support comparatively much higher power pulses [8]. However, their energy storage capacity is less than that of batteries (Table 1).

Therefore, hybridization of battery energy storage system (BESS) with supercapacitor storage system (SCSS) will lead to the overall ESS to possess high energy density and high power density (Figure 1) with increased operational flexibility [9]. Moreover, with this hybridization of these complementary characteristics the requirements of the system can be decoupled with each hybrid energy storage system (HESS) device performing to its characteristic potential and hence achieve reduced ESS sizing, investment cost and optimize the efficiency of the overall ESS [10,11].

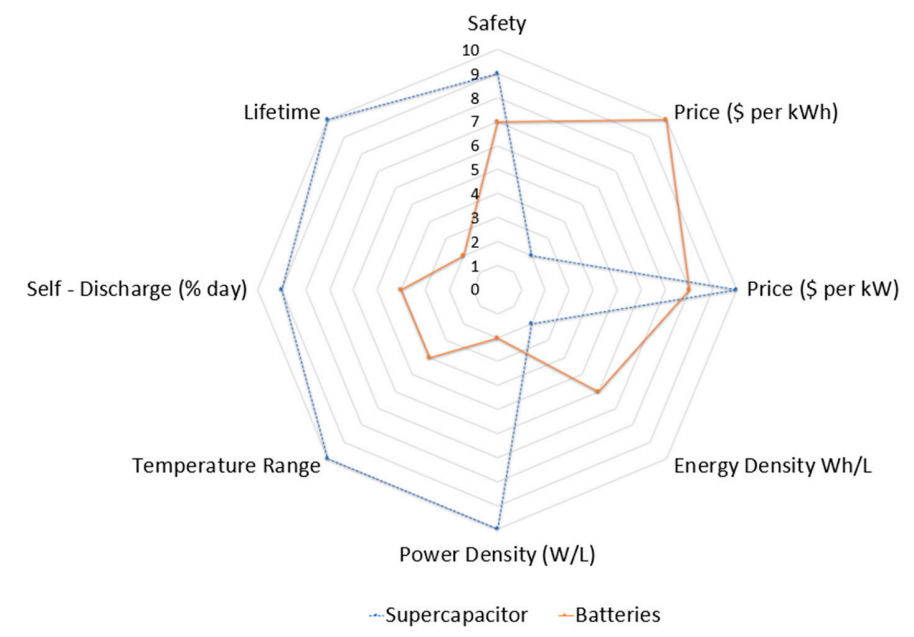

Figure 1. Qualitative comparison of batteries and supercapacitors. 
Table 1. Technical characteristics of selected energy storage systems.

\begin{tabular}{|c|c|c|c|c|c|c|}
\hline Characteristics & Supercapacitor & Lead-Acid & Li-Ion & $\mathrm{NaS}$ & $\begin{array}{l}\text { Redox-Flow } \\
\text { (VRB) }\end{array}$ & ZEBRA \\
\hline $\begin{array}{l}\text { Power Ratings } \\
\text { (MW) }\end{array}$ & $0-0.03[12,13]$ & $0-20[12,13]$ & $0-0.01[12,13]$ & $0.05-8[12,13]$ & $0.03-3[12,13]$ & $\begin{array}{c}0-0.3[12] \\
50[13]\end{array}$ \\
\hline $\begin{array}{l}\text { Energy Density, } \\
\text { Wh/L }\end{array}$ & $2-10[12,14]$ & $\begin{array}{c}50-80[12] \\
50-100[14]\end{array}$ & $\begin{array}{l}200-500[12] \\
200-350[14]\end{array}$ & $150-250[12,14]$ & $\begin{array}{c}16-33[12,15] \\
20-70[14]\end{array}$ & $150-180$ [12] \\
\hline Power Density, W/L & $100,000+[12]$ & $10-400$ [12] & & & & $220-300[12]$ \\
\hline $\begin{array}{l}\text { Specific Energy, } \\
\text { Wh/kg }\end{array}$ & $0.05-5[12]$ & $30-50[12,13,16]$ & $\begin{array}{c}75-200[12] \\
100-200[16] \\
150-350[13]\end{array}$ & $\begin{array}{l}150-240[12] \\
120[16]\end{array}$ & $\begin{array}{l}10-30[12] \\
30-50[16]\end{array}$ & $\begin{array}{c}100-120[12] \\
120[16]\end{array}$ \\
\hline $\begin{array}{l}\text { Specific Power, } \\
\text { W/kg }\end{array}$ & $\sim 100,000$ [12] & $\begin{array}{c}75-300[12,13] \\
180[16]\end{array}$ & $\begin{array}{c}150-315[12] \\
500-2000[13,16]\end{array}$ & $\begin{array}{l}150-230[12] \\
150-240[16]\end{array}$ & $80-150$ [16] & $\begin{array}{c}150-200[12] \\
174[16]\end{array}$ \\
\hline $\begin{array}{l}\text { Power Capital Cost, } \\
\$ / \mathbf{k W}\end{array}$ & $100-300[12]$ & $300-600$ [12] & $1200-4000$ [12] & $1000-3000$ [12] & $600-1500$ [12] & $150-300[12]$ \\
\hline $\begin{array}{c}\text { Energy Capital Cost, } \\
\$ / k W h\end{array}$ & $300-2000$ [12] & $200-400$ [12] & $600-2500$ [12] & $300-500[12]$ & $150-1000$ [12] & $100-200[12]$ \\
\hline $\begin{array}{c}\text { Capital Cost, } \\
\text { c/kWh-per cycle }\end{array}$ & $2-20[12]$ & $20-100[12]$ & $15-100$ [12] & $8-20[12]$ & $5-80[12]$ & $5-10$ [12] \\
\hline Reaction time, ms & $<10[14]$ & $3-5[14]$ & $3-5[14]$ & $3-5[14]$ & $>1000[14]$ & \\
\hline $\begin{array}{l}\text { Self-Discharge rate, } \\
\% \text { per day }\end{array}$ & $\begin{array}{l}20-40[12,16] \\
\leq 25[14]\end{array}$ & $\begin{array}{c}0.1-0.3[12,13] \\
0.1-0.4[14] \\
0.1-0.2[16]\end{array}$ & $\begin{array}{c}0.1-0.3[12,13] \\
0.03[16]\end{array}$ & $\begin{array}{l}\sim 20[1] \\
10[14]\end{array}$ & $\begin{array}{c}\text { Small [12] } \\
0.1-0.4[14]\end{array}$ & $\begin{array}{l}\sim 15[12] \\
20[16]\end{array}$ \\
\hline Discharge Time & $\mathrm{ms}-60 \mathrm{~min}[12,13]$ & sec-hr $[12,13]$ & min-hr $[12,13]$ & sec-hr $[12,13]$ & sec-10 h $[12,13]$ & $\begin{array}{l}\text { sec-hr [12] } \\
2-5 \mathrm{hr}[13]\end{array}$ \\
\hline Life Cycles & $50,000[12,13]$ & $\begin{array}{c}500-1000[12] \\
2000-4500[13]\end{array}$ & $\begin{array}{c}1000-10,000[12] \\
1500-4500[13]\end{array}$ & $\begin{array}{c}2500[12] \\
2500-4500[13] \\
\end{array}$ & $\begin{array}{c}12,000+[12] \\
10,000-13,000[13,15] \\
\end{array}$ & $\begin{array}{c}2500[12] \\
2500-3000[13] \\
\end{array}$ \\
\hline Lifetimes, years & $\begin{array}{c}5[12] \\
15[14] \\
10-12[16]\end{array}$ & $5-15[12-14,16]$ & $\begin{array}{c}5-15[12,13] \\
5-20[14]\end{array}$ & $\begin{array}{l}10-15[12] \\
15-20[14]\end{array}$ & $\begin{array}{c}5-10[12] \\
10-15[14]\end{array}$ & $10-14$ [12] \\
\hline Overall Efficiency & $0.75-0.83$ [14] & $\begin{array}{c}0.70-0.90[12,13] \\
0.70-0.75[14]\end{array}$ & $\begin{array}{l}0.80-0.85[14] \\
0.85-0.95[13]\end{array}$ & $\begin{array}{c}0.75-90[12,13] \\
0.68-0.75[14]\end{array}$ & $\begin{array}{c}0.85[12,15] \\
0.7-0.8[14] \\
0.65-0.85[13]\end{array}$ & $0.86-0.88$ [13] \\
\hline $\begin{array}{l}\text { Operation Range } \\
\text { Temperature, }{ }^{\circ} \mathrm{C}\end{array}$ & -40 to 75 [17] & -5 to $40[13,15]$ & -30 to $60[18,19]$ & $\begin{array}{c}300 \text { to } 350[12] \\
270-350[13]\end{array}$ & $\begin{array}{l}10 \text { to } 35[13] \\
0 \text { to } 40[15]\end{array}$ & -40 to 70 [12] \\
\hline
\end{tabular}

Several remarkable and brilliant reviews and studies have been presented over the last decade or so [20-27], which have meticulously outlined the: (1) descriptive topologies of HESS; (2) critical analytical comparison of HESS topologies; (3) topologies for active wind power suppression; (4) comprehensive critical reviews of HESS control strategies for power quality improvement in microgrids and (5) descriptive reviews on HESS control strategies in EVs. Consequently, there is a need to elucidate and organize these multi-dimensional applications, to highlight the versatile potential as well as the progress achieved by BESS-SCSS HESS in various multi-disciplinary fields. In this review, the objective is focused to analyze and outline the multi-functional applicative scope of hybrid BESS-SCSS energy storage systems based on proven contemporary research studies and investigation. The advancements achieved in each field of applications; with in-depth discussion on the applied control strategies is discussed. Therefore, the aim is to provide a technically informative as well as suggestive review for research potential in industrial and research fields.

The remainder of this paper is structured as follows: The topological investigations and their respective applications as well as their assets and liabilities are presented in Section 2. Section 3 elaborates on the efficacy of BESS-SCSS hybrid storages for power smoothening and dispatchability in terms of intermittent RESs; extensive contemporary control theories is presented for standalone, grid connected and large-scale RES systems. Section 4 discusses realization of various advanced power management strategies that this HESS has to offer in terms of power flow management concerning meticulous demand-generation equalization pertaining to future power networks with RESs. In accordance, the feasibility and support that can be offered with the complementary characteristics of HESS for power quality improvement and contingency support such as voltage regulation, primary frequency and inertia support, contribution for establishment of uninterruptible power supply for numerous load profiles and explicit and implicit support provided during black start process of distributed network systems is covered in Section 5. In Section 6, electric vehicle enhancement with 
the integration of BESS-SCSS HESS in described and detailed in depth for the purpose of optimizing ESS size, improvement in system efficiency, achievement of light weight vehicles, incremental driving range and hill climbing endurance. In this front, efficient harnessing of regenerative braking that can be effectively achieved in the field of EVs and locomotive that contributes to its autonomy is presented in Section 7. Finally, new and emerging concepts of applications in wireless power transfer in the areas of wireless node improvement, wireless RESs power transfer and medical instruments is discussed in Section 8, followed by conclusions in Section 9.

\section{Topologies of Hybrid Energy Storage System and its Applications}

Several topological investigations and innovations have been explored to enhance the HESS integration. The topological classification presented in this section is based on the connection of BESS and SCSS to the grid as well as the number of electronic interfaces.

A number of studies have been conducted to analyze and quantify the extent of this HESS combination [28]. A comparative study between ESS and HESS is presented in [29], where the authors present a semi-active topology in which SCSS absorbs abrupt peak power fluctuations with BESS passively connected to the wind turbine generator (WTG), regulating the DC link voltage and absorbing the low power fluctuations. In comparison to the conventional single type BESS based ESS, the power rating and lifetime of the BESS can be enhanced, effectively reducing the overall system losses. In [30] the same authors further investigated the power smoothing effectively of HESS using active topological integration methodology with high pass filter for power splitting of low and high power frequency of intermittent wind power generators. Further, the study in [31], investigates the effect of power smoothing of standalone photovoltaic (PV) system for static and dynamic loads. Fluctuations can be minimized with only-BESS, however with the integration of SCSS as a storage buffer for high power fluctuations, the battery power rating can be decreased that increases batteries efficiency for peak shaving and valley filling.

A study based on passively connected HESS for system stabilization with intermittent load-generation for remote area is presented in [32], based on theoretical and numerical analysis the authors suggest a superior stabilization performance can be realized in comparison to single BESS-only configuration, however, since in a passively connected configuration terminal voltage of the HESS is uncontrollable thus lowering the flexibility in control of HESS. Further, passive and semi-active HESS topologies are studied in [33], using a rule-based controller and Power frequency based filtration control, comparative analysis between the two topologies is concluded. In case of passive topology, while easy to implement, is uncontrollable for DC-link voltage regulation that can be subjugated by the semi-active topology, improving BESS SoC condition by reducing its peak current.

Furthermore, an investigative comparison is presented in [34], between the efficiencies of a single energy storage system and hybrid energy storage system consisting of BESS-SCSS. The study posits that in the former case efficiency of BESS drops severely when its output power is lower than 0.2 p.u. of its rated power. However, for the latter case of HESS, BESS goes into standby mode when the difference between the PV converters and the grid inverter is less than 0.2 p.u. of the BESS-rated power, diverting the control to SCSS until its recovery. In [35], a novel methodology is proposed for HESS sizing for improving grid stability under power fluctuations of renewable energy sources. This study proposes a genetic algorithm to establish an optimal RES and HESS size with the objective to reduce the adverse RES fluctuation effects and supply around 20 percent of the load requirement within a reasonable cost.

The concept of multi-level HESS in proposed in studies [28,36]. The methodology proposes the idea of implementing primary BESS, secondary BESS and an SCSS. These topologies help to improve the overall the ESSs life expectancy; therefore, power allocation is divided into low, medium and high frequencies respective to primary BESS, secondary BESS and SCSS [36]. Therefore, lead-acid batteries are considered as primary BESS, and Li-ion batteries constituting a comparatively lower power rating is taken as secondary BESS; this configuration provides a pragmatic approach to HESS implementation as low life expectancy of commonly preferred lead-acid battery leads to low reliability of BESS, that can 
be compensated by techno-economic integration of Li-ion batteries. Ultimately, the flexibility and reliability of operation is more enhanced specifically for standalone/ rural electrification scenarios [28].

Accordingly, an active-parallel BESS-SCSS interface has been proposed [37], considering SCSS as an energy storage buffer for abrupt high power demands, allowing the bus voltage to float with BESS SoC. Therefore, this configuration provides flexible controllability of both BESS and SCSS. In [38], a new architecture using DC side cascaded PI controllers for individual HESS is proposed. This architecture decouples the controllability of the DC and AC components, maintaining load-generation intermittency and further providing the flexibility of integration to any vendor-specific inverter integration. In [39] and [40], the authors proposed modular HESS, in contrast to the bi-directional DC-DC converter, providing flexibility and high power integration to the DC-link. The modular HESS provides integration of n-phase-shift-controlled dual active bridge connecting multiple BESS and SCSS for consistent power flow under varying load conditions and PV generation and further, have the potential to achieve zero voltage switching (ZVS) [41] for all the switches for the entirety of the load range through multi-port bi-directional converters.

In [42], a modulation strategy to interface HESS with the AC side through a three-level neutral clap inverter topology is proposed. Although with limited flexibility, the proposed inverter controls both the AC side voltage and current of HESS, hence reducing the effects of RES fluctuations and load variations. A novel two-input bi-directional converter based on a standard single phase inverter module is proposed in [43], to avoid extensive computation and possess a superior dynamic response. In this topology HESS is integrated into the dc link by a two-input four-switch $\mathrm{H}$-bridge bidirectional converter, controlling its charge/discharge states and hence overcome the load-generation mismatch.

Accordingly, cascading a double three-level inverter [44], the proposed direct integration scheme is based on dual inverter topology where a BESS and an SCSS bank are directly connected to the dc-link of the auxiliary inverter. Further, for investigating this topology a modified support vector machine (SVM) technique has been proposed to address the problems of dynamic voltage variations and unavoidable unbalanced conditions. Accordingly, a novel H-bridge based direct AC integration of HESS is investigated in [45-47]. The concept of direct AC integration is based on the fact it reduces the number of the power converters and eventually the power processing stages, reducing the power losses that comes with it and hence contributing to the increment of the system efficiency.

\section{Power Smoothing}

\subsection{Renewable Energy Sources/Supply Side Management}

Renewable energy sources are considered among the most effective methods to resolve energy shortage and to implement government regulations that aim to prevent global warming. RES is implemented in two ways, called grid-connected and standalone renewable power system (SARPS). Commonly employed renewable sources, such as wind and solar energy sources are influenced by weather and geographical conditions, making the sources highly unpredictable and uncontrollable in nature, and eventually, the output power produced will be highly unreliable to satisfy a standard power quality grid requirement to meet the required load demand, this greatly limits its capacity of integration. Fluctuating power commonly causes detrimental frequency and or voltage deviation that may reduce the lifetime of load appliances or damage them.

Moreover, the perturbation of generated power, as well as forecasting errors, limits RES dispatchability in a power network during a period of future time as it might be hazardous to power quality and system security, with the increased need to allocate reserved rotational power in the system. At the same time, the intermittent energy constitutes a significant part of the total power production capability of RES imposing the need for energy storage system (ESS) to function as a buffer that ideally, with the hybridization of slow and fast dynamics, an effective exploitation with SCSS absorbing abrupt high-power fluctuation and BESS, low power fluctuation can be achieved. 
Based on this theory, studies in [48-51], presented the smoothing effect of BESS-SCSS based HESS implementation in RES powered microgrid. In [49] and [50], with the bidirectional interface of HESS, a simple power frequency based allocation control strategy is proposed that aims at suppressing the output fluctuating power of RES using bi-directional ESS interface and hence optimize the system losses and maintenance cost of the overall system. In [51], experimental validation is presented to justify the feasibility of HESS for RES power smoothing. Based on the study, a viable utilization of RES can be possible through the optimal harnessing of short-term high-power fluctuation through SCSS which, inadvertently decreases BESS current stress level and hence increase the overall service life of the ESS. Hence, the HESS integration, consisting of BESS-SCSS, with RES is an interesting option for peak shaving and power smoothing in RES micro-grid.

The study in [52] presents the advantages of hybridization of SCSS with BESS, hence reducing the heat level and peak current surges in BESS which increases the transfer efficiency of the stored PV power to the load. Further, SCSS acts as a buffer that reduces the number of BESS cycle induced by the fluctuating solar irradiance. An optimal HESS based on model predictive control (MPC) control is designed and analyzed in [53], the proposed system can regulate the DC-link voltage, making it possible for the utility power grid or its users to draw constant dispatch power from RES, even in presence of RES perturbation. Recently, with the progression in ocean wave energy extraction technology [54], the effectiveness of HESS has been studied for smoothing oscillating power from wave energy conversion system (WECS) $[55,56]$. In this respect the BESS and SCSS are designed for energy and power requirement respectively, in addition to the optimal power extraction and allocation, it has been recorded that a considerable amount of cost saving can be accomplished even with the additional costs of the power electronics devices.

Several studies have been done on power allocation techniques and criteria for RES output power smoothing. The research work in [57], instigates that BESS-SCSS hybridized ESS optimally smoothens solar irradiance fluctuations. Working on a solar-powered standalone system, ESS is connected on point of common coupling (PCC) of dc link through bidirectional converters. Hence, SCSS can be utilized for peak and high-powered power demands, inadvertently extending BESS lifetime. A simple power fluctuation based isolation (PFI) energy management [58] is proposed for an active HESS topology for wind power smoothing, lowering the need for reserve energy in the grid. Similarly, in [59], a novel multi-objective power management for HESS to suppress PV power fluctuation is proposed. A linear weighted summation algorithm based on variable weights is proposed to obtain an optimal power-sharing ratio between the HESS, achieving the main optimization targets, reservation of state of charge of SCSS and minimization of power losses. By maintaining the state of charge of SCSS the proposed algorithm proves to be advantageous as SoC of SCSS can be effectively reserved to respond to future peak power demand.

In [60], HESS implementation has been studied for the prevention of grid voltage and frequency instabilities caused by wind integration, particularly in weak AC grids. Employing the combination of SCSS for short- high power transience and BESS for slow- low power fluctuations, the analysis shows a significant reduction in fluctuations of delivered power to the grid. In [61], smoothing of wind-solar output power fluctuation is proposed based on PFI and hysteresis controller for maintaining HESS SoC, ensuring a more controllable output power. In [62], four quadrant power operation of HESS is presented to compensate the active and reactive power fluctuation of wind power. The BESS is coupled with the DC- link voltage, absorbing power fluctuation between $0.01 \sim 0.1 \mathrm{~Hz}$ and accordingly, SCSS absorbs the higher power fluctuations that effectively reduces the system power losses and BESS cost.

A new approach is presented in [63], for power smoothing in micro-grids with large wind power penetration. Designing of low pass filters (LPF) and high pass filters (HPF) for splitting the low and high-power fluctuation is achieved by wind forecasting, that is based on empirical mode decomposition (EMD) analysis of historical wind data. An artificial neural network, for short-term and long-term HESS support, is then implemented to form an optimal association with the level of smoothness of the power delivered to the load, in accordance to the grid codes, and the corresponding economical HESS 
capacity required. The study in [64], investigates the implementation of higher order butter-worth LPF/HPF for optimal power allocation between BESS and SCSS. The author posits that designing higher-order filter can not only smoothen the output wind power but also the system's depreciation cost, due to charge/discharge of HESS, can be minimized. Further, to overcome the design limitations of linear based PI controller $[65,66]$, a non-linear sliding mode controller (SMC) is proposed in order to smooth the variable RES output power. In comparison to traditional linear controllers, that are designed and limited to operate around an operating point and hence lack good response with huge power variations, the proposed non-linear SMC controller suitably responses independently of the SoC of SCSS making the controller robust and applicable to varied power fluctuation scenarios. In $[67,68]$, a novel model predictive control strategy of ESS aimed to maintain grid voltage stability due to PV power intermittency has been studied. To avoid over-sized ESS due over charge/discharge, the MPC controller is designed to continuously predict accurate grid impedance and other system parameters by rolling optimization, as the real values remain constant over time. Hence MPC can simultaneously control the SoC of ESS without a delay through better accuracy and robustness parameter prediction. Since the control parameters are calculated with locally measured data, communication between PV and ESS is not required.

To eliminate the adverse effects of integrating fluctuating PV power resources to a utility network, a non-counter current mode control technique is proposed in [69]. According to the relationship between PV generation and load and SoC states of BESS, the microgrid operation is divided into four states with an individual set of controls for each state. The work in [70], presents a novel rule-based cooperative control strategy is proposed for HESS to absorb the fluctuation power produced by various RES. The control strategy controls SC to absorb or release the high-frequency power and battery absorb or release the low-frequency one. Rules are used to prevent SC from limit capacity and keep SC working.

The study in [71], proposes a novel HESS-based power filtration method for mitigation of wind output power. An online-wavelet based coordination control scheme for the HESS is presented, consists of primary filter (PF) and secondary filter (SF) stages. Combined power output is obtained at the PF stage which fully satisfies the fluctuation mitigation requirement. While the SF stage smoothens the wind power fluctuations after the PF stage. The proper range of the BESS is maintained through remaining energy level feedback control. An economic-based HESS sizing study is presented in [72], for mitigation of intermittent wind speed. The author presents a kernel smoothing estimation method to reflect wind power distribution that facilitates HESS size specifications. Therefore, on the cumulative density function (CDF) obtained, BESS and SCSS are assigned and designed for their specified power fluctuation level and hence acts as a power buffer between the RES and the grid absorbing/releasing power according to the requirement.

A capacity allocation scheme is presented in [73], to negate the negative impact of transient wind power production in the balancing of variable load and generation systems. The research proposes a discrete Fourier transform (DFT) and spectral analysis method to decompose generated wind power output into four components, thus quantifying the HESS requirement for peak shaving operation. The objective is to partially smooth the output wind power, considering only the unbalanced power quality requirement of the system rather than its economic significance. Hence, from the obtained results the author postulates that the power and energy ratings of HESS in partial smoothing mode decreases significantly in comparison with those in fully smoothing mode.

In [74], optimal utilization of HESS using adaptive power-sharing strategy is presented, optimally controlling the state of charge of SCSS for dynamic response to PV fluctuation, and further BESS smoothens electric quantity in the long timescale. Hence, achieving Peak shaving and PV's smoothing. In [75], a power smoothing methodology presented based on the proposition of a novel SCSS energy controller (SCEC). It this study, the author hypothesizes that due to nonlinearities the traditional supercapacitor voltage controller (SCVC) experiences difficulties to obtain a precise sizing and filter parameters for the allocation power frequencies that can be circumvented by the proposed SCEC. 
To support this theory, a demonstration has been presented on a single-phase grid-connected BESS-SCSS HESS framework, based on which can be concluded that, in addition to SCSS precise size and accurate calculation of filter parameters leading to an acceptable degree of RES output power smoothing, the required size of the SCSS in comparison to SCVC is significantly lower.

\section{Dispatchability of Renewable Sources}

In the context of optimal RES dispatch, studies considering the power smoothing, planning and scheduling of RES output power has been presented in this section. The study described in [76] proposes a two-level ESS for optimal dispatch of WTG under intermittent wind conditions. The control strategy is implemented to utilize HESS for short-term as well as a long-term capacity requirement with SCSS and BESS respectively. Similarly in [77], for the purpose of scheduling and dispatching a knowledge-based two level ESS control scheme is presented for mitigating wind power fluctuation and hence reduce dumped wind energy power. In [78], SCSS-BESS hybrid ESS is employed to accommodate output power fluctuations of PMSG based WTG for making the RES dispatchable for the power grid. The grid side controller employs voltage source inverter (VSI) for power quality conditioning, ESS becomes necessary as the fluctuating nature of WTG energy is detrimental for VSI to operate, hence ESS can help accommodate the difference between fluctuating wind power and that dispatched to the grid by absorbing the extra energy from the DC-link and releasing the stored energy to the DC-link when required.

Based on empirical mode decomposition analysis of wind data, an energy management technique is proposed in [79], for short-term wind dispatch. The authors integrated a pumped-hydroelectric storage system (PHS) in conjunction with the existing BESS-SCSS hybrid energy storage, thereby splitting the power fluctuation into high, medium and low that can be buffered with SCSS, BESS and PHS respectively. In [80], economical dispatching for a large scale WTGs is presented. The operation of SCSS and BESS are compartmentalized to compensate for short-term and long-term stable dispatch of stable power into the grid respectively, using a zero-phase low-pass filter for power allocation and committing BESS to average dispatching method.

Accordingly, PSO optimization is implemented to get the smoothing time constant for the applied filter in each dispatching interval. A short-term smoothing based on HESS is presented in [81], for short-term and ultra-short-term dynamic dispatch of a large-scale wind farm in a utility network. A hierarchical dispatch and control frame with generator units, wind farm, and power grid are proposed for optimal dispatch. Further, considering cost minimization of BESS-SCSS SoC and other constraints such as power losses, service life, cost of operation and maintenance an optimization algorithm based on PSO is established. In [82], a rule-based heuristic power management scheme has been investigated for dispatching large-scale PV for reduction of SCSS to one-fifth the size of BESS rating. The same authors in [83], implemented a robust rule-based algorithm to maintain the dispatch-ability of large-scale PV by power fluctuation control under large forecasting error (of $60 \%$ ). In [84], a statistical based approach is presented to overcome the random power generations of WTGs to achieve a balanced power quality for dispatching against a feasible cost of HESS. A power coordination method is proposed for BESS and HESS that allows enhancement of BESS life span by constraining its ramp-rates.

\subsection{Load Side Management}

The power demand of different consumers varies in accordance to their activities. This results in a variable and unpredictable load profile and consequently the load on a power station is never constant nor predictable. Many complexities of modern power system operation arise due to this inherent variability of the load demand. These type of variation causes harmonics, variability in voltage magnitude and poor power factor. In practical commercial considerations, these variations can be neglected, but are limited to the variations of heavy loads, for instance, standalone RES systems usually installed in remote areas away from the main grid for water irrigation requires starting DC motors 
resulting in high inrush currents, protection systems of oil and gas pipelines, telecommunication repeater stations, etc. results in pulse discharges of ESS. Therefore, ESS is important for a micro-grid in terms of system stabilization due to unpredictable and or abrupt load variations. It can improve the power quality of the system to make sure that the load in this system works properly. Moreover, in case of hybrid microgrid with a DC Bus and an AC Bus, the ESS should be charged appropriately to function as an energy backup for the load of the overall grid-interconnected system that in addition includes various sensitive loads. Therefore, in this section, various research studies will be depicted to outline the degree of permeability BESS-SCSS HESS can achieve.

The study in [85], demonstrates the capabilities of HESS for satisfying a decoupled load profile. In this proposition suitable rule-based control strategies for various operational modes are outlined to maintain the power supply to the mean load requirements and the HESS compensates the transient power and peak power demands. Similarly, in [86], PI regulators (LPF/HPF)-based power frequency splitting technique is presented for HESS power-sharing, full filling the load demand while maintaining the integrity of DC bus voltage and SoC conditions of HESS components. In [87] and [88], to overcome inconvenient voltage transients due to abrupt load variations an energy management strategy (EMS) is proposed utilizing the HESS framework. Here, a typical closed-loop control strategy is implemented for BESS and a rule-based fuzzy logic controller (FLC) is designed for SCSS for optimally utilizing individual strength of BESS and SCSS to compensate for average and transient load power demands. Therefore, an enhanced DC voltage recovery time can be achieved.

The research work in [89], deals with the allocation of loads with respectively low and high frequencies to suitable HESS components. In this study, a distributed multi-agent cooperative control method to balance the energy level of BESS in DC isolated microgrid with distributed energy storage is proposed for implementing a virtual impedance-based control, without the use of filters. In addition, this approach offers advantages in terms of robustness, extensibility, and flexibility in supplying power to varying load conditions.

Accordingly, considering the line impedance, a decentralized energy management strategy based on an enhanced mixed droop control strategy for autonomous DC microgrid is proposed in [90], based on a virtual resistance and virtual inductance droop control scheme. SCSS buffers fast transient load power flow with BESS providing only average load power demand. In [91,92], a controller is designed to distribute the load currents between BESS and HESS. A novel optimal power EMS is presented considering minimization fuel consumption in a hybrid AC-DC microgrid. In this study, the strategy is based on the ideology of optimization of BESS through diverting high short-term peak current to SCSS and hence obtain an economically feasible SCSS rating. A thorough observation of the capability of HESS, to maintain grid integrity while satisfying various classification of load profiles should be highlighted. In [93], a BESS-SCSS control strategy has been proposed to improve both transients in a MG bus and reduce the unbalanced power consumption in BESS. The SCSS compensates transient power for sudden load reducing the voltage dip on the AC bus that eventually regulates the unbalanced power demand under single-phase load, while the battery provides the balanced power in steady state.

In [94], a proposition is made for dynamic load distribution based on an equivalent series resistance control. In the proposed control method, the estimated average load power is supplied by BESS, and the remaining dynamic load power is distributed based on the equivalent series resistance-ratio of BESS to SCSS and the SoC of the SCSS. This proves to be beneficial in terms of system efficiency and overall energy loss. In [95], the capability of HESS to supply peak power requirement is presented. A SVM load predictive energy management system is proposed that predicts load requirements with $100 \%$ accuracy with classification time of 0.004866 seconds. Based on this instantaneous predicted load profile it has been absorbed that the HESS can flexibly satisfy peak load requirement without any delay. Further, the proposed SVM model reduces the need for bi-directional converters, reducing the system cost and power conversion systems (PCS) losses. 
Accordingly, a capacity distribution method is proposed in [96], for HESS planning in a microgrid coordinated with the load demand management. Based on Monte Carlo simulation (MCS) a statistical model is developed for RES and loads that determine the capacity of the HESS, providing more flexibility to choose than in a deterministic-based model as the capacities for different cumulative probability levels are determined. Moreover, implementation of hysteresis loop control (HLC), in lieu of the conventional PI-filter-based control strategy, reduces the BESS size to a certain extent while increasing the capacity of SCSS.

\section{Demand-Generation Power Flow Management}

Energy generated by renewable energy sources has many advantages over conventional supplies, especially for remote areas, however, the load demand being stochastic in nature with an unpredictable power supply can complicate grid stabilization for maintaining a continuous power supply. The system faces power quality issues such as voltage deviation and in microgrids with hybrid loads, the magnitude and frequency of the AC loads can get severely compromised. Energy storage systems in an electric generation and supply system provide the flexibility to decouple the generation and supply demand. Appropriate integration of RES with ESS allows an economical market penetration as well as emission and energy savings [97].

In [98], the stress reduction of BESS is explored with the integration of SCSS in the ESS framework to actively compensate the demand-generation randomness. With the construction of active parallel topology of PV-HESS and a closed loop based on HPF power allocation strategy, it can be highlighted that with is the hybridization of SCSS, the characteristic flaw of BESS to actively respond to transient power variations to maintain acceptable voltage profile can be circumvented. Further, the HESS optimization remains constant even for varied load profile cases [99-101]. Additionally, the HESS can also be effectively utilized for peak shaving [102] and valley filling operations [103], hence improving the power quality of the RES microgrid. An evolutionary algorithm is proposed [104], for an economic optimal sizing of HESS in a grid-connected DC microgrid considering the cost of power purchase from the grid, BESS-SCSS sizing, and continuous power supply for numerous load conditions.

A study reported in [105] demonstrates the effects of integrating HESS in a distributed energy resource (DER) network. Considering parametric effects of the current on ESSs voltage-current characteristics, converters, filter, and controllers; a small signal modelling has been carried out to regulate the dynamics of the HESS around a steady operating point. Based on the values obtained a frequency domain analysis is done considering variations of power converter duty cycle as controller input with HESS current and DC bus voltage variations as state variables, and furthermore, the BESS-SCSS voltage and load profile as the external disturbance. Therefore, it has been observed that the power-sharing ratio between the HESS components is determined by the load requirements, the parametric conditions greatly impact the transient response and the control parameters affect the steady state current sharing ratio.

In [106], to maintain the mismatch between the available and the required power energy in a distributed generation (DG) system, a novel topology of HESS based on SCSS and shunt connected BESS is studied. In this scheme, the BESS supplies the constant compensatory power to the load and SCSS buffers the rapid short-term and high-power variations in the load and the generation profile, being integrated through buck converter and bi-directional converters respectively. In addition, a diode is incorporated in parallel connection to BESS and SCSS that enables the power flow between the HESS components. Therefore, the voltage of SCSS can be maintained through BESS, charging it in the process and further reducing the BESS capacity size by nearly half. The proposal in [107], demonstrates the capability of HESS to deal variable RES generation and load variations in a grid-connected configuration. This investigation was carried out through the implementation of moving average filters (MAF), in substitution to the traditional low pass filter-based controllers. The MAF suitably distinguishes between the DC and AC components of the imbalanced power and accordingly delivers DC part to the BESS irrespective of the power fluctuation, with SCSS absorbing the AC part. Hence this 
configuration significantly relieves battery stress and SCSS maintain the DC bus voltage ensures no damage to the converters of the grid and the wind turbine.

Furthermore, several control strategies proposals have been postulated that strive to optimally solve the power mismatch issues. Novel control strategies have been briefly studied in [108-116]. Firstly, similar to conventional power frequency split (PFS) technique that compensates for random variation in solar irradiance the power is split into high and low frequencies controlling the duty ratios of the SCSS and BESS respectively. Further, considering the slow dynamic response of BESS, the author further proposes a closed-loop control that extracts the uncompensated error component from the BESS that additionally controls the SCSS duty cycle. Hence, increasing the controllability of DC-voltage regulation under load-generation mismatch conditions even without the need for dump loads [117], nevertheless, the BESS stress is further reduced. This proposed design has been further enhanced to give a PI-fuzzy-based PFS technique [118], for effective reduction of BESS stress and hence achieve faster DC voltage restoration. The study in [119] proposed a novel FLC-HESS power management strategy considering applications to rural electrification. Here, a novel multi-input-multi-output (MIMO) FLC controller is proposed, wherein solar irradiance, DC bus voltage and DC bus current are the input and correspondingly in accordance to the power requirement of the system the author proposes suitable fuzzy sets to generate the signals required for the switching BESS and SCSS in combination with suitable respective duty cycles. This methodology ensures rapid response of SCSS in an event of system transients and hence reduces the current stress in BESS and inherently the maintenance cost; in this study, fast and linear transients were obtained for each month and that shows $70.84 \%$ if the BESS cycles being saved due to transient compensation provided from SCSS.

An energy management strategy is presented [120-122], for a wind-dominated system consisting of doubly fed induction generators (DFIGs), BESS, SCSS and dump loads. BESS is connected on the load side of the DC bus while SCSS on the wind converter. Here, to satisfy the demand-generation mismatch a power allocation is coordinated between the HESS components using HPF, coordinating the depth of discharge (DoD) of BESS within specified limits. In [123], wavelet decomposition and neural network based energy management strategy is presented to compensate for the power variation caused by the RES and loads. Under the description of a unified voltage standalone RES configuration, a three-level Haar wavelet is implemented that decomposes the power difference between the RES generation and the load into approximation component and detailed component. In accordance with the suitability of their characteristic properties, BESS and SCSS cater the approximation and detailed components respectively. Furthermore, an adaptive linear (ADALINE) neural network is applied to obtain the reference power for BESS as the exact reference power from the approximation component can violate the SoC limits of BESS. The proposed method is capable to optimally compensate power variations while maintaining a stable DC bus voltage through rapid charge/discharge of SCSS.

An adaptive power management scheme based on PFS technique is presented in [124], to maintain DC voltage variations owing to load-generation variation. The controller is designed in terms of coordinated switching of BESS and SCSS such that the load requirement is fulfilled while maintaining optimal DC voltage as well as suitable SCSS voltage range in terms of hardware security. Accordingly, a novel adaptive learning based optimization is proposed in [125], the advantages, in contrast to a rule-based and fuzzy control algorithm is that the control is not based on a set of predefined rules hence offering more flexibility and faster rate of convergence. In [126], a control strategy based on dynamic feedback linearization is studied to regulate the DC microgrid. In this proposed strategy, Thevenin's equivalent resistance model is constructed for PV, BESS and load as voltage source and resistance further, the DC link is substituted as equivalent capacitance, considering controllable variable used for DC voltage regulation. Therefore, under variable loading conditions, the DC bus voltage is regulated with the exploitation of SCSS and BESS being implemented as an energy reservoir. To avoid the losses due to power converters in DC integration direct AC integration of HESS has been studied.

A local energy management has been proposed for an active PV system (APS) in [127], a hierarchical control structure is designed for the different level of the control system based on the 
power preferences given by grid operator using weather and load forecasts. The reference output for HESS choppers is achieved through PI controllers whereas for grid inverter, a direct power controller is used. According to the state of the three sources, the energy management chooses a corresponding operating mode and calculates the power reference for each source. Hence, the PV system can be connected in accordance with the required grid code.

Moreover, a simple energy management strategy for a DC-coupled hybrid microgrid consisting of HESS is proposed [128], for optimal power-sharing between ESS and grid, to achieve DC voltage regulation with seamless mode transition and contribution to the improvement of power quality in the AC grid. The average power demand is shared between the grid and BESS with the proposed dynamic sharing coefficient and SCSS is used to reduce the stress in the BESS during sudden generation and load variations. In [129], a small signal analysis presented for a two loop control strategy for DC voltage regulation. The applied control strategy generates a reference current for PV, BESS and SCSS converters based on the average of DC link voltage controller output. Thus, a single DC link voltage controller is used for DC link voltage regulation in all the operating modes (namely grid, storage and renewable dominating modes), through an outer voltage control loop and inner average current control loop that changes depending on which source is maintaining in DC link voltage due to which grid, battery, and PV current control loops are designed high bandwidth.

A novel EMS is proposed based on virtual adaptive impedance control technique of HESS [130,131]. This strategy provides the flexibility of installing multiple SCSS at different locations. In order to properly control SCs with different initial SoC, an adaptive virtual impedance droop control method is utilized that includes a virtual resistor and virtual capacitor to provide surge current compensation that controls the SoC of SC during surge current compensation. By using this control method, the SCSS with a higher level of SoC supplies more energy while absorbing less energy during the compensation and hence all SCs have a more balanced SoC towards the end of the compensation cycle. In addition, modularity of SCSS can be achieved as communications among different SCSS units is not required. A power management strategy is proposed in [132], for maintaining power flow balance in a renewable integrated microgrid. The main objective of power management is to maintain the SoC condition of BESS and HESS, delivering continuous power to the load. Based on the controllability of BESS power, the reference power generation for BESS is the main parametric component of the algorithm, deciding the operational states whether to stay in an islanded mode or take support from the grid.

\section{Grid Regulations and Fault Support}

Integration of RES into the AC grid is growing very rapidly to meet the high and reliable load demand. This leads to the introduction of unique new power quality challenges with further penetration and growing of the microgrid structure within the distribution network. Nevertheless, it is mandatory to maintain the voltage and frequency within the prescribed limits under any condition of the RES and load demand. Hence, the integration of ESS becomes extremely important to regulate RES and load accordingly. The sharing of power among grid, RES, and ESS plays a very vital role in the stable operation of a grid-integrated microgrid system. The stable operation of ESS, therefore, becomes a common denominator that maintains the power quality and system stability during the transitional operation of the overall grid.

\subsection{Voltage Regulation}

The study in [133], provides an economical and investigative framework for DC bus voltage regulation using HESS. In this investigation, a detailed graphical representation depicts the variability and sensitivity of power allocation between BESS-SCSS through reference current generation. Furthermore, in combination with a distinctive cost analysis, the study establishes an optimal number of supercapacitor concurrent to the filter cut-off constant; inherently reducing the overall system losses. In [134], a voltage based energy management scheme is presented. Using small signal control gains for designing current and voltage control loops, SCSS is utilized solely to respond to quick load fluctuation 
and BESS covering average load demand, a faster dc-link voltage regulation with optimal current level in both BESS and SCSS is achieved. The research described in [135], formulates the methodology for making a PV-HESS system work a classical generator. A systematic control strategy is proposed for a grid-tied PV system, the HESS coordinately controls the DC bus while an active/reactive power control strategy is implemented on the DC/AC inverters. In this set-up, a smooth power flow is maintained between the main grid and the RES grid owing to the characteristics of the HESS that actively overshadows the negative effects of power transience in the grid and hence allows a sustainable PV-HESS participation in the voltage regulation of the grid. In this regard, the work in [136], strives to overcome the power fluctuations and LVRT for a grid-interactive WTG farm. In this study, an enhanced active/reactive EMS is propositioned for a modular based power conditioner that consists of an integrated STATCOM-HESS on the DC side of the H-bridge, via a bi-directional DC-DC chopper. Hence, using a universal three stage decoupling control technique, cascaded STATCOM provides reactive power support, even in fault conditions and active power management, that is, wind power fluctuation is smoothened by HESS. In [137], a study is presented to highlight the contribution of RES-HESS for mitigating of power imbalance and abrupt frequency variations in a hybrid AC/DC grid. For achieving this, suitable reference values are generated for RES, power converters of HESS and the grid connecting voltage source converter (VSC), using a control algorithm. Therefore, HESS mitigates the power imbalance in the DC grid, reducing its negative impact on the VSC and hence enhancing the VSC operational support to help compensate the frequency variations in the AC grid.

These characteristics can be further implemented in the case of implementing dual voltage source inverter (DVSI) grid inverters [138]. Therefore, with the properties of BESS-SCSS HESS to maintain a dynamic power balance between different energy sources and sinks, empowering the DVSI to maintain the power quality of the power shared between the AC and the DC zones. Moreover, in an islanded mode of operation, DVSI scheme regulates a perfect sinusoidal voltage at PCC through auxiliary inverters, improving power quality at the PCC, which is a very essential aspect in a microgrid, while the main inverter of DVSI ensures power transfer between AC and DC zones. Further, in this perspective, the operation of dynamic voltage restorer (DVR) can be enhanced to mitigate voltage sag and voltage swell at the grid side, with the DVR being regulated by MPC [139] and powered by the DC microgrid consisting of RES-BESS-SCSS. A non-linear flatness control strategy is presented in [140], to manage energy flow in domestic autonomous hybrid power systems. The advantage of the proposed strategy is that without solving differential equations the output variables can be known and hence, the desired trajectory can be planned to maintain flat output. Considering voltage profiles of SCSS and the DC-link voltage, SCSS can provide/absorb power needed to control its voltage and hence the DC-link voltage under permissible limits and the power flow can be maintained to compensate the power between inconsistent load and generation.

In accordance, a new unified power quality conditioner (UPQC) configuration is presented in [141], mitigating voltage interruption taking into account current harmonics, current unbalance, load reactive power, voltage sag, voltage swell, and voltage fluctuation. The UPQC consists of shunt inverter, that ensures a balanced sinusoidal and unity power factor at the PCC through a current injection under normal condition and operating in voltage control mode to maintain balanced sinusoidal load voltage under voltage interruption. Moreover, a series inverter injects voltage to ensure balanced and sinusoidal load voltage, isolating the inverter under voltage interruptions. The HESS is integrated into the shunt and series inverters, with BESS delivering average load power during voltage interruption and SCSS providing load peak power fluctuation. The study in [142] investigates DC microgrid with HESS and posits a novel power management strategy for the integration of unstable RES DC grid to traditional grid power supply network. The DC bus voltage is employed as a carrier to represent operation modes of the system based on critical DC voltage conditions, the control strategy automatically judges and switches within the specified seven ranges of power operation state formed by six critical DC bus voltages. 
Further, a unified adaptive energy management system is proposed [143,144] for a residential grid integrated PV based hybrid microgrid with BESS-SCSS energy storage system. The proposed EMS ensures reliable and continuous power supply to various local loads and enables the bidirectional real power transfer between microgrid and utility grid while maintaining the grid standards at the PCC through VSC. Smooth mode transfer of grid, hierarchical load shedding, off-MPP operation in excess mode and fast DC link voltage regulation are the considered features of the proposed EMS. In addition, the EMS minimizes the power drawn from the grid and maximizes the power injection during peak pricing and can effectively operate without forecasting and voltage measurement of the HESS.

\subsection{Frequency and Inertia Support}

The study in [145], demonstrates the contribution of HESS to the inertial response in power systems with high penetration of RES. To demonstrate this, a virtual inertia emulator has been formulated essentially consisting of three-phase inverter and an output LC filter. In combination with the characteristic of HESS an efficient virtual synchronous generator can be formulated that actively contributes to the inertia of the overall system. In [146], the introduction of the working principle of virtual synchronous generators (VSG) with the configuration of HESS is studied for enhancing the frequency stability of the system. A novel control strategy is proposed by which BESS provides the low-frequency part of the frequency deviation and SCSS the high-frequency deviation part for VSG system.

The study in [147], exploits the BESS-SCSS HESS characteristics to enhance the primary frequency control (PFC) and the inertial response in a power grid. In this study, a configuration in which SCSS enhances inertia response and BESS support towards PFC has been presented on a two area system model in which one area is only composed of conventional energy sources and other with increased penetration of RES has been tested. Modelling and sizing of SCSS have been performed based on the rate of change of frequency (RoCoF) whereas BESS is done to meet the steady-state frequency deviation limit. In [148], the concept of frequency coordinating virtual impedance is proposed for autonomous control of a DC microgrid. The control strategy enables an effective power frequency split for BESS and SCSS for a seamless transition even in grid integrated systems. Furthermore, this methodology ensures more operational flexibility in comparison to conventional droop control methods through coordination multiple converters in dual timescale and power-scale. In [9], a frequency regulation strategy is proposed in a grid-connected microgrid with high penetration of wind farms. The strategy is based on maintaining a power balance between the generation and the load. Based on the power imbalance caused by the wind farm the power is divided into small, medium and large power fluctuations, which are compensated and smoothened, by BESS, SCSS and conventional grid generators. Based on this power frequency split methodology and a proposed computational technique for choosing optimal cut-off frequencies for the low and medium frequency a sizing methodology of HESS is proposed.

\subsection{Uninterruptible Power Supply and Fault Support}

In [149], an investigation has been performed to identify the potential of HESS as a backup uninterruptible power supply (UPS) during short grid failure intervals. Based on this study, it has been observed that HESS can effectively ensure compensation for the whole load requirement during an outage lasting less than 10 seconds. However, considering the high cost of SCSS, for this case scenario, it should be pointed out that the system conceived would be efficient with at least four times BESS lifetime extension. Accordingly, a fault ride-through control scheme is presented in [150,151], with BESS for DC link voltage regulation and SCSS supporting large transience in the system. This topology consists of two parallel bidirectional converters, for BESS and SCSS respectively, with the additional inclusion of switches, making it suitable for short-circuit fault tolerant and further proposed the control scheme for the converter is designed as such to reduce the losses due to these additions of switches. A PI-based DC voltage regulation scheme is proposed in [152], that aims to ensure continuity of power 
supply regardless of the load behavior and variation of solar irradiation. Maintaining the SoC, the duty ratios of HESS is controlled, via, the power flow variation projected as voltage variation at the DC-link.

Control strategies for DC voltage regulation in case grid-connected and islanded operation are presented in $[153,154]$. In grid operation, Renewable sources supply power to the loads and DC voltage controlled by the inverter maintaining optimum power flow, while the AC bus is controlled by the utility. However, EMS in islanded mode/utility fault conditions maintains magnitude and frequency of the AC zone by controlling storage to regulate DC bus and inverter as a voltage source to regulate magnitude and frequency of the AC bus. Hence, to maintain power quality of the power supplied from RES, the voltage of HESS is regulated to supply power in both DC and AC zones. This strategy maintains low power flow between utility and microgrid, reducing the influence of the load-generation fluctuant into the utility and regulating DC bus voltage under any load profile. A capacity optimization of HESS is proposed in [155], aiming to reduce the one-time investment and operational costs of the system. Based on utilization rate and reliability constraints, optimal HESS capacity is obtained through a simulated annealing particle swarm optimization (SAPSO) algorithm. Therefore, the designed HESS capacity has the potential to fully absorb maximum surplus power of the fluctuant RES and maintain a continuity of power supply to sensitive loads under unstable weather conditions through maximum power loss process. In [156], the operation of HESS combined with micro-combined heat and power (CHP) generation is investigated for uninterruptible power supply to the heat loads and the electrical loads. In this investigation, a novel control scheme where CHP is dispatched to meet the heating load and the HESS reconciles any mismatch between the electrical load and CHP generations. Similarly, implementation of HESS in hybrid RES system consisting of PV-wind-Diesel [157], paves the way for optimal utilization of various energy sources and hence reduce the fuel consumption.

Similarly the study in [158], provides a descriptive investigation to achieve an uninterruptible power supply by implemented HESS as power backups in DER systems. With BESS providing the base DC loads and SCSS acts as storage buffer to cope with large transient of the system. In [159] maximum power point tracking (MPPT) control using extreme search control (ESC) principle combined with SMC (to avoid the need for wind speed forecasting) is used for extraction of maximum power from the stand-alone wind resource and over-generation and under generation of wind power is coped with fully active HESS employing a simple current controlled power-sharing scheme based on the current level of the charge/discharge current between BESS and SCSS, that is, BESS absorbs all the excess power if the current level is lower than the predefined threshold current value. Further, if the power generated is low, SCSS discharges when the discharging current is too high. Hence, achieving rapid response to maintain the power balance in a wind power system with variations in both wind velocity and load power. The work has been further extended to a grid-tied system in [160], (to simulate an uninterrupted power supply) with WTG as a primary source of power supply. Here MPPT is achieved through optimal torque (OT)-based control. An experimental study employing a coordinated band control strategy is presented in [161], for reliable supply to both AC and DC loads in an autonomous PV-wind- diesel generation system. The objective of the system is to maintain the voltage at the DC PCC, to hence maintain the overall system stability, so under normal conditions with no significant power variation, DC voltage is regulated by SCSS whereas in if the state capacity of SCSS is not under its specified low/high operation bands, BESS replaces SCSS under a specified voltage band for voltage stabilization. Further, in cases where the power supply remains to be continuously lower than the power demand, in this case, diesel generator acts as a backup supply to maintain DC link voltage.

\subsection{Black Start}

In contrast to the complicated restoration process of conventional power systems that is carried out according to predefined guidelines, the whole restoration process is much simpler in case of distributed generation micro-grid due to the reduced number of controllable variables (micro-sources, loads and switches). However, due to the unpredictability and transience of the micro-sources, they are unsuitable for direct connections to the microgrid. In such cases, different PCS such as DC/AC, 
$\mathrm{AC} / \mathrm{DC} / \mathrm{AC}$ converter interface is required. Furthermore, considering a worst-case scenario in which fully controllable synchronous generators are absent that would control the voltage, frequency and balance the load and generation conditions of the grid, the operations of the energy source converter interface hence play a key role to emulate a synchronous generator operational support to allow islanded mode microgrid operation. In these situations, ESS coupled with PCS usually injects active power into the grid proportional to the frequency deviation.

The role of ESS is very important in order to maintain the stability of the system as they handle the transient requirement of the system [162], usually modelled as constant DC voltage sources, coupled with VSI in cases of gird connected microgrid, and inject active power into the grid in proportion to the frequency deviation at least during the initial stages of black-start process. Correspondingly, the amount of power to be connected should consider the capacity of the ESS in order to avoid any significant voltage and frequency deviation. Therefore, during the black-start process, auxiliary power requirements are compensated by the BESS and transient power by SCSS [132]. The study in [163], presents a simulative evaluating the performance of BESS-SCSS HESS in various black-start conditions of $55 \mathrm{~kW}$ asynchronous motors. The rating of BESS and SCSS are $250 \mathrm{~kW} / 250 \mathrm{kWh}$ with V/F control and $50 \mathrm{~kW} / 10$ seconds with $\mathrm{P} / \mathrm{Q}$ control respectively. Accordingly, at the start up the SCSS is positioned to compensate for the inrush current generated at the start process of the asynchronous generator. Hence it has been observed that BESS-SCSS HESS can successfully support the power quality requirements during direct start, star delta start, and frequency conversion start conditions and maintain continuous power supply during these conditions.

\section{Storage Enhancement in Electric Vehicular Application}

The energy source is the heart of a hybrid EV. Despite the environmental benefits provided by EVs, the main obstacle of electric propulsion still lies in the ESS. The success of this new transportation option can be only achieved if the ESS offers features, such as reasonable costs, long life cycle, fast charging time with efficient acceleration and mileage [164]. The primary energy sources presently used in automotive systems are batteries and fuel cells. In order to reduce their costs, the current needs to be decreased and stabilized so it is not very erratic. An investigative based review is presented in [27,165], addressing various type BESS and SCSS for hybridization with different topologies, further outlining various optimization objectives, such as maximization of driving range and service life of BESS or minimization of component stress or satisfying load demand and maintaining optimal power flow. In accordance, this section presents various technological advancements achieved with HESS incorporation in EVs.

\subsection{Optimal Storage Sizing and Improved Storage Efficiency}

The studies in [166-169], elaborates on the current input smoothing of BESS when hybridized with SCSS. This is demonstrated using a simple parallel active topological integration of HESS, with suitable converter control and with the ideology that, SCSS acts as an energy buffer to compensate for peak and short-term transient power requirements. This improves the efficiency of the overall ESS system as the current level in BESS reduces and hence can be effectively used for long term energy requirements with a comparatively lower rating. Moreover, SCSS having lower resistance shields BESS from at least a portion of the current pulses that prevents the sulfating of BESS and hence increases BESS lifetime. Therefore, without degradation of EV standards, the load requirement can be effectively met with reduced cost. A fuzzy logic EMS proposed in [170], that is concerned with the smoothing of battery current profile while controlling the SoC of SCSS. Implementation of a multi-input converter (MIC) interface for controllability convenience and to establish a flexible energy flow between BESS and SCSS, the proposed EMS successfully decreases the power peaks and hence increases BESS life by about $55 \%$. Sizing is an important criterion as big SCSS is harmful and costly. HESSs used in EVs, HEVs, and PHEVs are extremely important due to the limitations on the cost and relatively short lifetime of BESS [171]. Additionally, the cost of storage units installed on EVs represents a significant portion of the vehicle manufacturing cost. Therefore, the optimal sizing of the storage unit is a crucially important 
task for EV manufacturing industries. A brief comparative study is presented in [172], considering three configurations of BESS and/or SCSS is investigated to outline the advantages of HESS in comparison to the two standalone ESS configuration. The optimal sizing is realized through a modified particle swarm optimization (PSO), based on which enhancements such as reduced ESS rating, reduced ESS component stress and improved SoC conditions of ESS components, can be easily achieved.

Further, in [173], a zero voltage transition (ZVT) interface is presented to exhibit peak power capabilities of HESS. This interface guarantees soft switching ensuring an optimal converter efficiency and, moreover, allows the regulation of voltage considering the power flow direction, hence limiting the current level. In [174], a control strategy is demonstrated that aims to reduce the peak power drawn from the source. Considering a limited computational power and limited load forecasts, a two-level control scheme is proposed that samples the load requirements and individual peak load thresholds and further, maintain the integrity of the HESS. This scheme proposes the idea of HESS to compensate for residual power between the load and the source which in comparison to MPC operation of peak power minimization has lower computational time and faster dynamic characteristics. In accordance for BESS current profile smoothing, an optimized HESS sizing can be formulated [175], characteristic relationship equations of BESS-SCSS voltage to the line voltage with the capacity constraints based favorable HESS SoC conditions. A general perk of BESS-SCSS HESS is its property to compensate for peak power load requirements. This helps to ensure a cost-efficient operation as peak power requires additional resources that adversely affect the system reliability and storage lifetime. Moreover, load dynamics are fast, often not perfectly known as a priori and the computational forecast are generally limited, making traditional optimal control difficult. SCSS implementation as an auxiliary element beside BESS increases the peak power capability of HESS and BESS lifetime.

In $[176,177]$, a cost optimization strategy related to the daily operational cost for a light rail vehicle system is proposed. For achieving this, a multi-objective genetic algorithm (GA) is implemented that considers the optimization of the degradation cost of the HESS that is aimed to prolong its replacement period and the investment costs. Based on this, a suitable HESS rating is obtained that, in comparison to the presented rule-based control (RBC) scheme minimizes the daily operational cost of the tramway system by $13.9 \%$ and $21 \%$ with the inclusion of unscheduled stops. Therefore, this strategy while satisfactorily supplies the power and energy demand even in the catenary-less zones, it provides a certain degree of autonomy to the tramway in case of unexpected events with low operational costs.

\subsection{Reduction of Electric Vehicular Weight}

Taking into consideration a limited total mass of HESS [178], an optimal sizing and EMS is proposed to improve the BESS life cycle and driving mileage of an electric race car. The author proposes a bi-level multi-objective sizing and control framework based on non-dominated sorting genetic algorithm-II and FLC, hence an optimized membership function of FLC based control is obtained in the sizing algorithm. Further, this multi-objective approach provides the flexibility of choosing favorable HESS sizing for various other applications of EV optimization. Further, to overcome saturation as well as decrease the weight of EVs due to an oversized electronic interface, a second parallel SCSS topology is presented in [179], which allows a decrease in the number of the current smoothing inductances of SCSS. In $[180,181]$, introduces an optimization algorithm potentially to decrease the BESS operational size by minimization of magnitude and fluctuation of the battery current. This algorithm considers the unpredictability of the load requirement in an EV based on which SCSS reference voltage is regulated which computes a sub-optimal value for the reference current in BESS. Hence an optimal size and increased life expectancy are achieved that is robust in terms of the inaccuracy of future load predictions of EVs. FC stack is a high-temperature proton exchange membrane fuel cell, which is fueled with hydrogen produced by an onboard reformer. Hybridization with BESS-SCSS [182] predominantly diminishes the size of the fuel cell.

Accordingly, in [183], presents the advancements achieved with the integration of HESS with fuel cell-hybrid electric vehicles (FC-HEVs). The topological integration consists of fuel cells (FCs) directly 
connected to the inverter DC bus and a three-port isolated triple-half-bridge (THB) converter, with a multi-winding transformer is implemented to interface the low voltage BESS and SCSS HESS. Based on the load profiles a power management strategy is presented that aims to achieve the maximum fuel economy with light ESS mass and higher system efficiency. In this design the FC is controlled to provide the average power, BESS provides the medium-level long term peak power requirements and SCSS is assigned to absorb the regenerative braking energy and respond to short term peak power requirements of the FC-HEV. Therefore, leading to a decoupled power management and in addition, the THB converter permits wide SCSS voltage variation and flexibility in current control of BESS.

Similarly, in [184], considering the optimization of FC-HEVs, a two-quadrant converter is used for integration of FC-BESS-SCSS to the DC-link. HESS topology is proposed for DC voltage regulation in a fuel cell hybrid vehicle (FCHV). In this study, a total of six PI-based control loop applied pertaining to DC voltage control, SCSS voltage and BESS current control. The author proposes to utilize FC and BESS for steady-state power supply, in addition, BESS is utilized for assisting FC during start-ups. Consequently, SCSS can compensate for the peak power requirement of the system that can greatly reduce the stress of FC-BESS devices and significantly impact the overall size of the vehicle.

\subsection{Driving Range Improvement}

Commonly, HEVs use an internal combustion engine (ICE) and ESS that powers the electric motor. These HEVs either capture energy from regenerative braking or the combustion engine through the spinning of an electrical generator or prolong the charge on their BESS. Further, several HEVs reduce their emission and fuel consumption by shutting down the ICE when idle. The objective here is to achieve a smaller HEV engine that may run at various speeds, providing better efficiency. To optimize these objectives, BESS-SCSS HESS proves to be a beneficial option. In [185], the objective aims to meet the load demand and maintain optimal dynamic performance in diesel-based HEV. This work focuses on the principal utilization of multiple energy sources for satisfying the given load so that the integrity of each energy source can be well maintained, for this objective, a power flow energy management is proposed taking into consideration the DC-link voltage, fuel consumption of a Diesel generator, SoC of SCSS.

Moreover, integration of HESS significantly optimizes the fuel consumption of the Diesel generator, for instance, in [186], a heterogeneous optimization is realized that actively achieves lower ratings for numerous energy sources with the cost optimizations in cases of various scenarios of climatic conditions, economics, and autonomy of the EV. In [187], an optimization method is proposed to minimize fuel consumption and losses in EV and PHEV. The optimization is based on the estimation of driving cycle of the vehicle that determines an optimal size of BESS and SCSS and the degree of hybridization required, extending battery life and minimizing the system losses. This control strategy takes into consideration the power reference generation of BESS, regulation of SCSS's state of charge and forecast control based on driver commands, proposing a novel power-sharing energy management technique. The authors in [188] address the objective to quantitatively minimize both system cost and battery degradation considering the requirement of minimal mileage in EVs. Taking into account a typical city bus driving cycle, non-dominating genetic algorithm (NSGA) is proposed to achieve these objectives for a semi-active topological framework. Therefore, with the objectives achieved at suitable HESS operational temperature (between $15{ }^{\circ} \mathrm{C}$ to $40{ }^{\circ} \mathrm{C}$ ), it has been concluded that a significant increment of $67 \%$ increase in the driving range is gained with HESS in comparison to BESS-alone operation.

Accordingly, the study in [189], presents an optimization algorithm based on dynamic programming (DP) for minimizing the operational costs, including the electricity costs and BESS degradation costs over the whole driving cycle of an electric bus. Considering, various HESS semi-active topological integration it can be concluded that about $50 \%$ of the ESS operational cost can be reduced in comparison to BESS-only configurations. Furthermore, a detailed comparative analysis is presented for four different topologies of semi-active HESS configurations that are extensively researched in 
the literature. Based on the investigation the advantages of the topologies are presented based on initial HESS cost and operational costs. The study in [164] pursues to establish a trade-off between deprecation cost, installation cost, and energy efficiency. In this study two methodologies based on linear programming, based on peak power and energy capabilities of the ESS component and non-linear programming, designed to increase the accuracy for the loss models of the EV. Based on this formulation, in comparison to BESS-alone configuration, it has been observed that the overall cost of the system is decreased by almost $20 \%$ and further considering the driving cycle, the HESS saves up to $7.8 \%$ of the energy that significantly contributes in the increase of the EV range.

\section{Regenerative Braking}

The traditional braking system works on the principle of frictional forces acting between the brake pads and the wheels, in this the heat generated as the by-product is considered as a loss of energy and in some cases an additional expenditure, like high-performance vehicles in which an additional brake cooling system is employed to heat dissipation so that the vehicle can quickly regain its efficiency. In contrast to this regenerative braking system employed in the EVs has the potential to be feasibly recaptured. The electric motor in EVs that is used to drive the vehicle wheel plays a crucial part during the braking process. When the brake pedal is pressed, the regenerative braking circuit switches this motor and hence operates it in reverse for countering the direction of the wheels; hence the motor performs like a dynamo or a power generator that produces electrical energy.

Conventionally, a practical restriction exists on the quantity and intensity on the application of regenerative braking, as it is impossible to recover its full energy. The extractable amount of regenerative energy depends on many factors such as receptiveness of the energy storages and motor deceleration rate. For a short interval during fast deceleration, the power will be high. This means a significant amount of power is returned to the grid, relative to the power rating of the motor. Hence for capturing maximum energy, the volume of the storing energy should be equal to the change in kinetic energy. This recovered energy remarkably extends the range of EVs. The study in [190], elucidates the potential and benefits of harvesting regenerative braking energy with SCSS. Considering an active topological integration of the ESS, the author proposes a novel control strategy wherein the SCSS maintains constant dc load bus voltage due to voltage instability caused by regenerative braking. Utilizing a second-order low pass Bessel filter BESS is cleared off from rapid high pulsed transient power variations and is responsible in supplying only the average load variations and further at some instances, charge the SCSS and regulate the DC link voltage.

The study described in [191] proposes a novel HESS interface for recycling regenerative braking energy in HEVs taking into account an optimal SCSS sizing to achieve an economical solution for efficiency improvement of regenerative braking. Considering urban driving conditions where usually the motor speed remains below its half-rated value, therefore SCSS can be directly switched on during peak power demands at the DC-link, without the use of conventional DC-DC converters. This direct integration, considerably improves the regenerative energy recycling efficiency that can be visualized in case of a heavily hybridized HEV that demands a large ESS, SCSS interfacing satisfies the peak load demand of the HEV enabling internal combustion engine (ICE) and BESS to sustain only the base power demand, this leads to a major reduction in BESS and can also justify the increased cost of nominal SCSS. Using similar ideology an SCSS plug-in retrofit kit is proposed in [192] to primarily harvest the regenerative braking energy for light EVs. This research presents the concept of plug-in SCSS energy storage system that can be easily implemented into the system with two wires and current sensors as a momentarily auxiliary storage device. Here with a suitable control algorithm, the author demonstrates the HESS potential, which is to increase the lifetime of the HESS devices and its improved efficiency during the discharge process. In [193], a control strategy for effective garnering and employment of energy from regenerative braking is implicated. In this research, the author proposes a three-layer control strategy for optimal power interface of HESS in EV. The control scheme optimally maintains the current reference; power-sharing based on frequency isolation and energy conditions of HESS. 
In combination with the diversion of peak load demand to SCSS helps to enhance BESS service life with an overall increase in vehicle efficiency as SCSS can be more effectively utilized in regenerative braking.

In [194], a new regenerative braking system (RBS) based on HESS for EV driven by a brushless DC (BLDC) electric motor is proposed. In this research, a novel-switching template is formulated for the inverter operation, eliminating the need for additional power electronic interface and hence directly harvests the regenerative brake energy. This formulation involves establishing a braking force distribution, achieved through an artificial neural network (ANN) that ensures reliable and smooth brake operations and further, PI controllers are used for simultaneously adjusting the braking current to control the duty cycle of the inverter realizing a constant torque braking. Since the BLDC acts as a generator during braking conditions, the proposed switching algorithm boosts the DC-link voltage regulation ensuring an effective energy transfer that is enough in quantity either to enhance the acceleration or to be stored for assistance during uphill driving to avoid deep discharging of BESS.

The studies in $[195,196]$, in the context of regenerative energy, investigate various topologies for HESS integration in EV systems and further propose a novel topology that aims to satisfy the peak power demand with a reduced DC-DC converter size. In this proposition, the voltage of SCSS is maintained at a higher value than BESS, with BESS providing power directly only when SCSS voltage level drops below a preset value, hence smoothing the load profile for BESS. Considering this topology, the capabilities of SCSS effectively utilized in regenerative braking and BESS protection with an improvement in the driving ability of the vehicle at low temperatures. Correspondingly in [197], experimental quantification is presented to assess the increment in the recuperation of regenerative braking by hybridization of BESS with SCSS. In this work, a rule-based algorithm is implemented to offload the current peaks from BESS and set a power-mix between HESS based on load power prediction. Hence, increasing the maximum power capability of the EV and reduce capacity fade effects in cold climates.

The experimental research described in [198] investigates the HESS capability for harvesting energy from regenerative braking. It has been observed that hybridization of SCSS with BESS efficiently recuperates high power transfer under regenerative braking and acceleration, and therefore an EMS that can manage power flow to maintain SCSS voltage becomes the key parameter in reducing the overall system losses. Against this background the studies in [199,200], proposed a novel HESS interfacing strategy for the recuperation of regenerative braking energy, that is shared between BESS and SCSS. The configuration aims to regulate the DC-link voltage and reduce the converter switching losses thereby, utilizing the full capability of SCSS based on partial power processing, that is, HESS processes only a portion of vehicle power and is active only when supply power is needed from SCSS. The study in [182], investigates the effect of BESS rating when hybridized with SCSS. Using a degradation model of BESS, the effects of diverting the energy requirements during acceleration and deceleration is investigated. In Accordance, a multi-objective optimization oriented on DIviding RECTangles (DIRECT) algorithm is proposed to formulate an optimal trade-off size between HESS and standalone BESS system to fulfill the load requirements.

In further studies, a cost-based comparative study is presented in [201], that posits the implementation of ZEBRA (sodium-nickel chloride battery) with SCSS to demonstrate their performance in both acceleration and regenerative braking in EV. ZEBRA, being almost three times cheaper than Li-ion batteries with higher endurance, that can survive more than 1000 cycles while being almost discharged. In this study, the author demonstrates that this HESS arrangement can function almost equally to Li-ion-SCSS HESS combination in terms of increased range, increased acceleration, regenerative braking capabilities and enhanced efficiency of EV. However, the feasibility of this arrangement is limited to horizontal highways as the regenerative. The study in [202], investigates the recuperation potential of HESS in energy regeneration from the active suspension (AS) of HEVs. The AS loads are highly fluctuant in nature, so in this study, SCSS is directly responsible for the compensation of AS load requirements in terms that BESS is completely isolated from its influence. Further, outlining the size requirements and postulating the control approach, the author's observations 
suggest that the AS loads can be successfully augmented the HEV fuel consumption and emission. A short summary of selected comparative studies concerning different topological and control benefits used is presented in Table 2.

Table 2. Comparison study performed between different topologies and control strategies.

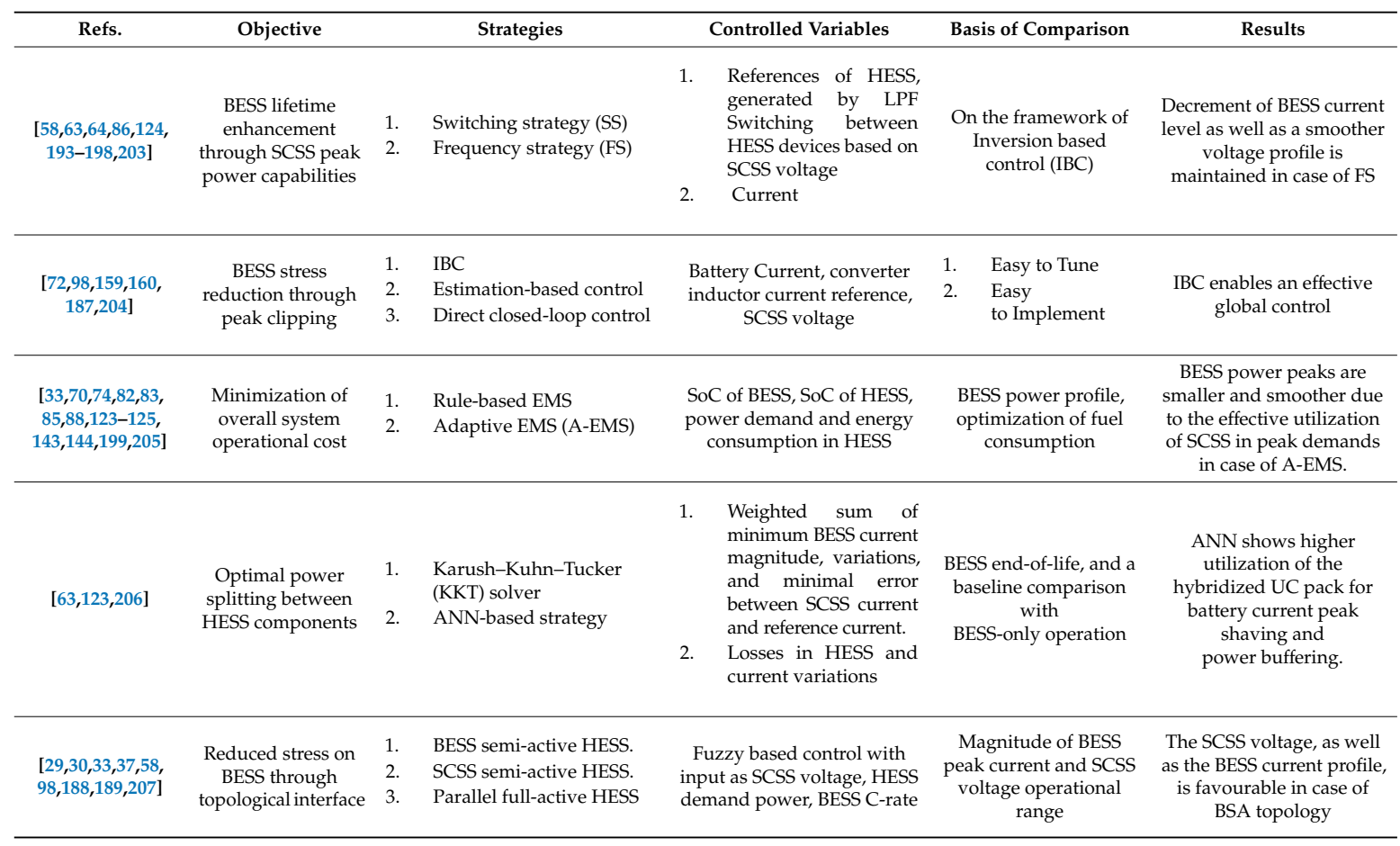

\section{Wireless Power Transfer}

The sensor nodes of wireless sensor networks (WSNs) are mostly inactive to achieve longer runtimes. Conventionally, power being mainly provided by BESS, which is either primary or secondary energy sources. However, considering high resistance of BESS a significant loss occurs due to sleep and leakage current, moreover due to internal BESS impedance a sizable voltage drop is also experienced at the activation instant of the node, limiting the required power to be extracted. Considering these anomalies, in [208], a parallel combination of BESS-SCSS HESS is proposed. Here, with a selection of three BESS, namely silver oxide batteries, lithium batteries and NiMH batteries, it has been observed that hybridization with SCSS is feasible with only the first two as the resistance of NiMH is already optimally low enough. However, for silver oxide and lithium batteries, the combination with a low resistance SCSS significantly increases the runtime of the sensor nodes with a feasible decrement in leakage current losses.

The properties of HESS have been exploited to enhance the feasibility of wireless power transfer (WPT) applications in EVs [209]. Here the authors proposed a three-mode energy management strategy based on the SoC conditions of HESS components. Hence, in addition, to regulating the energy input from the WPT and manage energy distribution between the BESS-SCSS this study proposes the implementation of a short period of negative current periods in the charging state of the DC-DC converters. This depolarization pulses significantly reduces the stress on the internal resistance of BESS. Accordingly, the study in [4], presents the architecture of HESS in PV based wireless sensor network. Proposing a sizing formulation for the HESS using a statistical approach on the historical power data, this study briefly addresses the improvement of HESS lifetime and endurance under fluctuating current conditions.

A wireless power supply with BESS-SCSS HESS has been developed for powering implantable devices, such as intracranial pressure (ICP) monitors in [210]. The shunt used to drain excess fluid 
from the brain in hydrocephalus patients fail regularly. Here, the most valuable diagnostic tool is a pressure sensor implanted in the brain. In this respect, WPT based on inductive power transfer technology is implemented on HESS where the HESS powered ICP can meet both the short- and long-term operational requirements, and further the study recorded that SCSS provides a quick charge back up for collection of data.

\section{Conclusions}

A comprehensive review outlining the applicative scope of BESS-SCSS-HESS has been presented. These application domains, consisting of renewable energy output power smoothing and their optimal dispatchability, load profile smoothing, overcoming demand-generation mismatch, power quality assurances during grid fault, support during distributed generation black-start procedures, contribution to system inertia, storage enhancement in EVs, improved extraction of regenerative braking and in wireless power transfer technology, have been categorized and subcategorized and independently discussed. This review also highlights strategies implemented in their respective applications and its potential benefit. This review paper aims to inform electric utilities that strive to maintain system power quality with the integration of large scale intermittent renewable energy sources and its associated challenges, electric vehicle system designers who aim to improve and compete for establishing and hence manufacture economical, reliable as well as pragmatic emission-less vehicles and locomotives, and finally industries in the field of medical instrumentation.

The status quo concerning environmental factors and depletion of existing resources introduced the concept of integrating renewables in the existing power grid. However, the intermittency and acute peak fluctuations of these renewable resources deem them to be a technical threat to the grid. Addition of BESS-SCSS-HESS serves as an energy buffer to meticulously smoothen the output power delivered according to load demand by addressing average power fluctuation and abrupt peak power fluctuation (due to shading of PV panels, unpredictable wind fluctuations, etc.). This not only improves the power quality of the grid but also significantly reduces the dependency on forecast values, increasing the reliability to establish a large-scale renewable power grid in terms of economical dispatchability. Moreover, the improved response of the hybrid energy storage serves as pertinent support to the grid-tied inverters and serves as extremely reliable backups in terms of short-term faults in the power system. Similarly, in case of heavy loading conditions, a more accurate peak shaving and demand response can be achieved with this principle. The major advantage of hybridization of batteries with supercapacitors is their complementary characteristics, therefore a considerable amount of current stress is deviated from batteries, owing to its low power density and hence a comparatively small battery rating is achieved. This can be observed with the application of BESS-SCSS-HESS in EVs. In this case, where the autonomy is the key commercialization factor, supercapacitors can act as an energy buffer during abrupt acceleration and hill climbing operations significantly reducing the weight of the EV. In addition, the characteristics of SCSS can be more effectively used to store energy produced during regenerative braking, increasing the mileage of EVs.

Extensive research has been done considering solar and wind power as energy sources, however, implementation of BESS-SCSS in ocean wave energy extraction is at its emerging stages. Similarly, limited work has been presented to enumerate the potential capability of BESS-SCSS-HESS in terms of inertial support and primary frequency control, which might be the key factor to quantify its permissibility in black-start process of, distributed generation systems. Finally, the application in wireless power transfer that enhances the runtime and voltage profile of the wireless nodes has research potential to be implemented in $\mathrm{PV}, \mathrm{EV}$, and biomedical devices but the research work performed is insufficient to conclude its viability in these fields. In further studies/publications, the contribution and efficacy of hybrid energy storage systems will be studied thoroughly to establish its feasibility and operational flexibility in future smart grids. 
Funding: Deanship of Research (DSR), at King Fahd University of Petroleum and Minerals (KFUPM), supported this work.

Acknowledgments: The author would like to acknowledge the support provided by the Deanship of Research (DSR) at King Fahd University of Petroleum \& Minerals (KFUPM) for funding this work through project No. RG171009. Also, we would like to acknowledge the funding support provided by the King Abdullah City for Atomic and Renewable Energy (K·A.CARE).

Conflicts of Interest: The authors declare no conflict of interest.

\section{Nomenclature}

\begin{tabular}{|c|c|}
\hline ANN & Artificial Neural Network \\
\hline AS & Active Suspension \\
\hline BESS & Battery Energy Storage System \\
\hline $\mathrm{CHP}$ & Combined Heat and Power \\
\hline DER & Distributed Energy Resources \\
\hline DFIG & Doubly-Fed Induction Generator \\
\hline DIRECT & DIviding RECTangle \\
\hline DoD & Depth of Discharge \\
\hline DVR & Dynamic Voltage Restorer \\
\hline EMD & Empirical Mode Decomposition \\
\hline DVSI & Dual Voltage Source Inverter \\
\hline EMS & Energy Management Strategy \\
\hline ESS & Energy Storage System \\
\hline EV & Electric Vehicles \\
\hline FC & Fuel Cell \\
\hline GA & Genetic Algorithm \\
\hline HESS & Hybrid Energy Storage System \\
\hline $\mathrm{HPF}$ & High Pass Filter \\
\hline ICE & Internal Combustion Engine \\
\hline ICP & Intracranial Pressure \\
\hline LPF & Low Pass Filter \\
\hline LVRT & Low Voltage Ride Through \\
\hline NSGA & Non-dominating Genetic Algorithm \\
\hline MIMO & Multi input multi output \\
\hline MPC & Model Predictive Control \\
\hline MPPT & Maximum Power Point Tracking \\
\hline PCC & Point of Common Coupling \\
\hline PCS & Power Conversion System \\
\hline PFC & Power Frequency Control \\
\hline PFI & Power Frequency based Isolation \\
\hline PFS & Power Frequency Split \\
\hline PHS & Pumped Hydroelectric Storage \\
\hline PV & Photovoltaic \\
\hline RBC & Rule-based control \\
\hline RES & Renewable Energy Sources \\
\hline RoCoF & Rate of Change of Frequency \\
\hline SC & Super Capacitor \\
\hline SCEC & Supercapacitor Energy Controller \\
\hline SCSS & Super Capacitor Storage System \\
\hline SCVC & Supercapacitor Voltage Controller \\
\hline SoC & State of Charge \\
\hline SVM & Support Vector Machine \\
\hline THB & Triple-Half-Bridge \\
\hline UPQC & Unified Power Quality Conditioner \\
\hline UPS & Uninterruptible Power Supply \\
\hline
\end{tabular}


VSC Voltage Source Converter

VSG Virtual Synchronous Generator

VSI Voltage Source Inverter

WPT Wireless Power Transfer

WTG Wind Turbine Generator

ZVS Zero Voltage Switching

ZVT Zero Voltage Transition

\section{References}

1. Lujano-Rojas, J.M.; Dufo-López, R.; Bernal-Agustín, J.L. Optimal sizing of small wind/battery systems considering the DC bus voltage stability effect on energy capture, wind speed variability, and load uncertainty. Appl. Energy 2012, 93, 404-412. [CrossRef]

2. Merei, G.; Moshövel, J.; Magnor, D.; Sauer, D.U. Optimization of self-consumption and techno-economic analysis of PV-battery systems in commercial applications. Appl. Energy 2016, 168, 171-178. [CrossRef]

3. Khalid, M.; Aguilera, R.P.; Savkin, A.V.; Agelidis, V.G. On maximizing profit of wind-battery supported power station based on wind power and energy price forecasting. Appl. Energy 2018, 211, 764-773. [CrossRef]

4. Ongaro, F.; Saggini, S.; Mattavelli, P. Li-Ion battery-supercapacitor hybrid storage system for a long lifetime, photovoltaic-based wireless sensor network. IEEE Trans. Power Electron. 2012, 27, 3944-3952. [CrossRef]

5. Li, L.; Li, X.; Wang, X.; Song, J.; He, K.; Li, C. Analysis of downshift's improvement to energy efficiency of an electric vehicle during regenerative braking. Appl. Energy 2016, 176, 125-137. [CrossRef]

6. Fiori, C.; Ahn, K.; Rakha, H.A. Power-based electric vehicle energy consumption model: Model development and validation. Appl. Energy 2016, 168, 257-268. [CrossRef]

7. Cicconi, P.; Landi, D.; Germani, M. Thermal analysis and simulation of a Li-ion battery pack for a lightweight commercial EV. Appl. Energy 2017, 192, 159-177. [CrossRef]

8. Kuperman, A.; Aharon, I. Battery-ultracapacitor hybrids for pulsed current loads: A review. Renew. Sustain. Energy Rev. 2011, 15, 981-992. [CrossRef]

9. Germanovich Chirkin, V.; Yurievich Lezhnev, L.; Anatolyevich Petrichenko, D.; Arkadyevich Papkin, I. A battery-supercapacitor hybrid energy storage system design and power management. Int. J. Pure Appl. Math. 2018, 119, 2621-2624.

10. Fan, F.; Huang, W.; Tai, N.; Zheng, X.; Hu, Y.; Ma, Z. A conditional depreciation balancing strategy for the equitable operation of extended hybrid energy storage systems. Appl. Energy 2018, 228, 1937-1952. [CrossRef]

11. Mesbahi, T.; Le Moigne, P.; Bartholomes, P.; Rizoug, N. Improved model of battery/supercapacitor hybrid energy storage system based on thermo-electrical and aging behaviors. In Proceedings of the 7th IET International Conference on Power Electronics, Machines and Drives (PEMD 2014), Manchester, UK, 8-10 April 2014.

12. Chen, H.; Cong, T.N.; Yang, W.; Tan, C.; Li, Y.; Ding, Y. Progress in electrical energy storage system: A critical review. Prog. Nat. Sci. 2009, 19, 291-312. [CrossRef]

13. Zakeri, B.; Syri, S. Electrical energy storage systems: A comparative life cycle cost analysis. Renew. Sustain. Energy Rev. 2015, 42, 569-596. [CrossRef]

14. Chirkin, V.G.; Khripach, N.A.; Petrichenko, D.A.; Papkin, B.A. A review of battery-supercapacitor hybrid energy storage system schemes for power systems applications. Int. J. Mech. Eng. Technol. 2017, 8, 699-707.

15. Rahman, F.; Rehman, S.; Abdul-Majeed, M.A. Overview of energy storage systems for storing electricity from renewable energy sources in Saudi Arabia. Renew. Sustain. Energy Rev. 2012, 16, 274-283. [CrossRef]

16. Nikolaidis, P.; Poullikkas, A. A comparative review of electrical energy storage systems for better sustainability. J. Power Technol. 2017, 97, 220-245.

17. Xiong, G.; Fischer, T.S.; Kundu, A. Influence of temperature on supercapacitor performance. In Thermal Effects in Supercapacitors; Springer: Berlin, Germany, 2015; pp. 71-114.

18. Divya, K.C.; Østergaard, J. Battery energy storage technology for power systems-An overview. Electr. Power Syst. Res. 2009, 79, 511-520. [CrossRef]

19. Ma, S.; Jiang, M.; Tao, P.; Song, C.; Wu, J.; Wang, J.; Deng, T.; Shang, W. Temperature effect and thermal impact in lithium-ion batteries: A review. Prog. Nat. Sci. Mater. Int. 2018, 28, 653-666. [CrossRef] 
20. Etxerberria, A.; Vechiu, I.; Vinassa, J.M.; Camblong, H. Hybrid energy storage systems for renewable energy sources integration in microgrids: A Review. In Proceedings of the 2010 Conference Proceedings IPEC, Singapore, 27-29 October 2010; pp. 144-149.

21. Yu, P.; Li, G.L.; Zhang, Y.; Cheng, Y.; Sun, S.M.; Zhao, P. The review on the topology of battery-supercapacitor hybrid system applied into the real-time wind power suppression. Adv. Mater. Res. 2013, 860-863, 287-292. [CrossRef]

22. Zimmermann, T.; Keil, P.; Hofmann, M.; Horsche, M.F.; Pichlmaier, S.; Jossen, A. Review of system topologies for hybrid electrical energy storage systems. J. Energy Storage 2016, 8, 78-90. [CrossRef]

23. Chotia, I.; Chowdhury, S. Battery storage and hybrid battery supercapacitor storage systems: A comparative critical review. In Proceedings of the 2015 IEEE Innovative Smart Grid Technologies-Asia (ISGT ASIA), Bangkok, Thailand, 3-6 November 2015.

24. Jing, W.; Lai, C.H.; Wong, S.H.W.; Wong, M.L.D. Battery-supercapacitor hybrid energy storage system in standalone DC microgrids: A review. IET Renew. Power Gener. 2017, 11, 461-469. [CrossRef]

25. Narvaez, A.; Cortes, C.; Trujillo, C.L. Comparative analysis of topologies for the interconnection of batteries and supercapacitors in a Hybrid Energy Storage System. In Proceedings of the 8th International Symposium on Power Electronics for Distributed Generation Systems (PEDG), Florianópolis, Brazil, 17-20 April 2017.

26. Mishra, R.; Saxena, R. Comprehensive review of control schemes for battery and super-capacitor energy storage system. In Proceedings of the 7th International Conference on Power Systems (ICPS), Pune, India, 21-23 December 2017; pp. 702-707.

27. Kouchachvili, L.; Yaïci, W.; Entchev, E. Hybrid battery/supercapacitor energy storage system for the electric vehicles. J. Power Sources 2018, 374, 237-248. [CrossRef]

28. Jing, W.; Lai, C.H.; Wong, W.S.H.; Wong, M.L.D. A comprehensive study of battery-supercapacitor hybrid energy storage system for standalone PV power system in rural electrification. Appl. Energy 2018, 224, 340-356. [CrossRef]

29. Li, W.; Joós, G. A power electronic interface for a battery supercapacitor hybrid energy storage system for wind applications. In Proceedings of the 39th IEEE Power Electronics Specialists Conference, Rhodes, Greece, 15-19 June 2008; pp. 1762-1768.

30. Li, W.; Joos, G.; Belanger, J. Real-time simulation of a wind turbine generator coupled with a battery supercapacitor energy storage system. IEEE Trans. Ind. Electron. 2010, 57, 1137-1145. [CrossRef]

31. Ramadan, R.; Yehia, D.M.; Rashad, E.M. Impact of hybrid energy storage system on solar power generation integrated in microgrids. In Proceedings of the 4th International Conference on Electric Power and Energy Conversion Systems (EPECS), Sharjah, UAE, 24-26 November 2015; pp. 1-5.

32. Ma, T.; Yang, H.; Lu, L. Development of hybrid battery-supercapacitor energy storage for remote area renewable energy systems. Appl. Energy 2015, 153, 56-62. [CrossRef]

33. Rout, T.; Maharana, M.K.; Chowdhury, A.; Samal, S. A comparative study of stand-alone photo-voltaic system with battery storage system and battery supercapacitor storage system. In Proceedings of the 4 th International Conference on Electrical Energy Systems (ICEES), Chennai, India, 7-9 February 2018.

34. Wang, G.; Ciobotaru, M.; Agelidis, V.G. PV power plant using hybrid energy storage system with improved efficiency. In Proceedings of the 2012 3rd IEEE International Symposium on Power Electronics for Distributed Generation Systems (PEDG), Aalborg, Denmark, 25-28 June 2012; pp. 808-813.

35. Ma, T.; Lashway, C.R.; Song, Y.; Mohammed, O. Optimal renewable energy farm and energy storage sizing method for future hybrid power system. In Proceedings of the 17th International Conference on Electrical Machines and Systems (ICEMS), Hangzhou, China, 22-25 October 2014; pp. 2827-2832.

36. Jing, W.; Lai, C.H.; Wong, W.S.H.; Wong, M.L.D. Dynamic power allocation of battery-supercapacitor hybrid energy storage for standalone PV microgrid applications. Sustain. Energy Technol. Assess. 2017, 22, 55-64. [CrossRef]

37. Niemoeller, B.A.; Krein, P.T. Battery-ultracapacitor active parallel interface with indirect control of battery current. In Proceedings of the 2010 Power and Energy Conference at Illinois (PECI), Urbana, IL, USA, 12-13 February 2010; pp. 12-19.

38. Deshpande, G.; Kamalasadan, S. An approach for micro grid management with hybrid energy storage system using batteries and ultra capacitors. In Proceedings of the 2014 IEEE PES General Meeting Conference \& Exposition, National Harbor, MD, USA, 27-31 July 2014. 
39. Zhou, H.Z.H.; Bhattacharya, T.; Khambadkone, A.M. Composite energy storage system using dynamic energy management in microgrid applications. In Proceedings of the International Power Electronics Conference (IPEC), Sapporo, Japan, 21-24 June 2010.

40. Zhou, H.; Bhattacharya, T.; Tran, D.; Siew, T.S.T.; Khambadkone, A.M. Composite energy storage system involving battery and ultracapacitor with dynamic energy management in microgrid applications. IEEE Trans. Power Electron. 2011, 26, 923-930. [CrossRef]

41. Ding, Z.; Wang, C.; Yang, C.; Xie, S. A novel soft-switching multiport bidirectional DC-DC converter for hybrid energy storage system. IEEE Trans. Power Electron. 2014, 29, 1595-1609. [CrossRef]

42. Vechiu, I.; Etxeberria, A.; Camblong, H.; Vinassa, J.M. Three-level neutral point clamped inverter interface for flow battery/supercapacitor energy storage system used for microgrids. In Proceedings of the Innovative Smart Grid Technologies Conference Europe, Manchester, UK, 5-8 December 2011.

43. Jose, J.J.; Manthati, U.B. Two-input bidirectional converter controlled hybrid energy storage system (HESS) for micro grids. In Proceedings of the 2016 IEEE 1st International Conference on Power Electronics, Intelligent Control and Energy Systems (ICPEICES), Delhi, India, 4-6 July 2016; pp. 1-4.

44. Jayasinghe, S.D.G.; Vilathgamuwa, D.M.; Madawala, U.K. A direct integration scheme for battery-supercapacitor hybrid energy storage systems with the use of grid side inverter. In Proceedings of the Twenty-Sixth Annual IEEE Applied Power Electronics Conference and Exposition (APEC), Fort Worth, TX, USA, 6-11 March 2011; pp. 1388-1393.

45. Abeywardana, D.B.W.; Hredzak, B.; Agelidis, V.G. A single phase grid integration scheme for battery-supercapacitor AC line hybrid storage system. In Proceedings of the 2014 IEEE International Conference on Industrial Technology (ICIT), Busan, Korea, 26 February-1 March 2014; pp. 235-240.

46. Abeywardana, D.B.W.; Hredzak, B.; Agelidis, V.G. Single-phase grid-connected LiFePO4 battery-supercapacitor hybrid energy storage system with interleaved boost inverter. IEEE Trans. Power Electron. 2015, 30, 5591-5604. [CrossRef]

47. Abeywardana, D.B.W.; Hredzak, B.; Agelidis, V.G. Battery-supercapacitor hybrid energy storage system with reduced low frequency input current ripple. In Proceedings of the 2015 International Conference on Renewable Energy Research and Applications (ICRERA), Palermo, Italy, 22-25 November 2015; pp. 328-332.

48. Akram, U.; Khalid, M. A Coordinated frequency regulation framework based on hybrid battery-ultracapacitor energy storage technologies. IEEE Access 2017, 6, 7310-7320. [CrossRef]

49. Jia, Y.; Oti, K.; Yamamura, N.; Ishida, M. A study on electric power smoothing system for lead-acid battery of stand-alone natural energy power system using EDLC. IEEJ Trans. Ind. Appl. 2007, 127, 1181-1189. [CrossRef]

50. Jia, Y.; Shibata, R.; Yamamura, N.; Ishida, M. Characteristics of smoothed-power output topology of stand-alone renewable power system using EDLC. In Proceedings of the 2006 37th IEEE Power Electronics Specialists Conference, Jeju, Korea, 18-22 June 2006.

51. Zhang, G.; Tang, X.; Qi, Z. Research on battery supercapacitor hybrid storage and its application in microgrid. Russ. J. Org. Chem. 2014, 50, 547-551.

52. Kan, S.Y.; Verwaal, M.; Broekhuizen, H. The use of battery-capacitor combinations in photovoltaic powered products. J. Power Sources 2006, 162, 971-974. [CrossRef]

53. Hu, X.; Tseng, K.J.J.; Srinivasan, M. Optimization of battery energy storage system with super-capacitor for renewable energy applications. In Proceedings of the 8th International Conference on Power Electronics-ECCE Asia, Jeju, Korea, 30 May-3 June 2011; pp. 1552-1557.

54. Von Jouanne, A.; Brekken, T.K.A.; Lettenmaier, T.; Amon, E.; Moran, S.; Yokochi, A. Advancing the wave energy industry. IEEE Potentials 2015, 34, 41-47. [CrossRef]

55. Hazra, S.; Bhattacharya, S. Hybrid energy storage system comprising of battery and ultra-capacitor for smoothing of oscillating wave energy. In Proceedings of the 2016 IEEE Energy Conversion Congress and Exposition (ECCE), Milwaukee, WI, USA, 18-22 September 2016.

56. Parwal, A.; Fregelius, M.; Temiz, I.; Göteman, M.; Oliveira, J.G.d.; Boström, C.; Leijon, M. Energy management for a grid-connected wave energy park through a hybrid energy storage system. Appl. Energy 2018, 231, 399-411. [CrossRef]

57. Liu, X.; Wang, P.; Loh, P.C.; Gao, F.; Choo, F.H. Control of hybrid battery/ultra-capacitor energy storage for stand-alone photovoltaic system. In Proceedings of the 2010 IEEE Energy Conversion Congress and Exposition, Atlanta, GA, USA, 12-16 September 2010; pp. 336-341. 
58. Sowmini, S.; Rajakumar, S. An energy storage system for wind turbine generators-Battery and supercapacitor. Int. J. Eng. Res. Appl. 2013, 3, 1219-1223.

59. Jiang, W.; Zhang, L.; Zhao, H.; Hu, R.; Huang, H. Research on power sharing strategy of hybrid energy storage system in photovoltaic power station based on multi-objective optimisation. IET Renew. Power Gener. 2016, 10, 575-583. [CrossRef]

60. Esmaili, A.; Novakovic, B.; Nasiri, A.; Abdel-Baqi, O. A hybrid system of li-ion capacitors and flow battery for dynamic wind energy support. IEEE Trans. Ind. Appl. 2013, 49, 1649-1657. [CrossRef]

61. Abbassi, A.; Dami, M.A.; Jemli, M. A statistical approach for hybrid energy storage system sizing based on capacity distributions in an autonomous PV/Wind power generation system. Renew. Energy 2017, 103, 81-93. [CrossRef]

62. Jia, H.; Fu, Y.; Zhang, Y.; He, W. Design of hybrid energy storage control system for wind farms based on flow battery and electric double-layer capacitor. In Proceedings of the 2010 Asia-Pacific Power and Energy Engineering Conference, Chengdu, China, 28-31 March 2010.

63. Yuan, Y.; Sun, C.; Li, M.; Choi, S.S.; Li, Q. Determination of optimal supercapacitor-lead-acid battery energy storage capacity for smoothing wind power using empirical mode decomposition and neural network. Electr. Power Syst. Res. 2015, 127, 323-331. [CrossRef]

64. Bai, L.; Li, F.; Hu, Q.; Cui, H.; Fang, X. Application of battery-supercapacitor energy storage system for smoothing wind power output: An optimal coordinated control strategy. In Proceedings of the 2016 IEEE Power and Energy Society General Meeting (PESGM), Boston, MA, USA, 17-21 July 2016; pp. 1-5.

65. Liu, F.; Liu, J.; Zhang, B.; Zhang, H.; Ul, H.S. Energy management of hybrid energy storage system (HESS) based on sliding mode control. In Proceedings of the IEEE 7th International Power Electronics and Motion Control Conference-ECCE Asia, Harbin, China, 2-5 June 2012; pp. 406-410.

66. Etxeberria, A.; Vechiu, I.; Camblong, H.; Vinassa, J.M. Comparison of sliding mode and PI control of a hybrid energy storage system in a microgrid application. Energy Procedia 2011, 12, 966-974. [CrossRef]

67. Lei, M.; Yang, Z.; Wang, Y.; Xu, H.; Meng, L.; Vasquez, J.C.; Guerrero, J.M. Design of energy storage control strategy to improve the PV system power quality. In Proceedings of the IECON 2016-42nd Annual Conference of the IEEE Industrial Electronics Society, Florence, Italy, 23-26 October 2016.

68. Lei, M.; Yang, Z.; Wang, Y.; Xu, H.; Meng, L.; Vasquez, J.C.; Guerrero, J.M. An MPC-based ESS control method for PV power smoothing applications. IEEE Trans. Power Electron. 2018, 33, 2136-2144. [CrossRef]

69. Geng, Y.; Hou, M.; Zhang, L.; Dong, F.; Jin, Z. An improved voltage control stratgy for DC microgrid with hybrid storage system. In Proceedings of the 2018 13th IEEE Conference on Industrial Electronics and Applications (ICIEA) 2018, Wuhan, China, 31 May-2 June 2018; pp. 958-962.

70. Ou, Y.; Wen, J.; Wang, L.; Yu, Z.; Huang, J.; Ai, Q.; Fen, L. A novel control strategy of super capacitor-battery energy storage system. In Proceedings of the 5th International Conference on Electric Utility Deregulation and Restructuring and Power Technologies (DRPT), Changsha, China, 26-29 November 2015; pp. 2089-2093.

71. Jiang, Q.; Hong, H. Wavelet-based capacity configuration and coordinated control of hybrid energy storage system for smoothing out wind power fluctuations. IEEE Trans. Power Syst. 2013, 28, 1363-1372. [CrossRef]

72. Wang, X.; Yue, M.; Muljadi, E. Probabilistic approach for power capacity specification of wind energy storage systems. IEEE Trans. Ind. Appl. 2014, 50, 1215-1224. [CrossRef]

73. Zhao, P.; Wang, J.; Dai, Y. Capacity allocation of a hybrid energy storage system for power system peak shaving at high wind power penetration level. Renew. Energy 2015, 75, 541-549. [CrossRef]

74. Sun, C.; Song, Y.; Xu, L.; Yuan, K.; Xue, Z.; Li, J.; Wu, Z.; Yang, X. A hybrid energy storage adaptive control strategy for PV power smoothing. In Proceedings of the 2017 IEEE Conference on Energy Internet and Energy System Integration (EI2), Beijing, China, 26-28 November 2018; pp. 1-4.

75. Abeywardana, D.B.W.; Hredzak, B.; Agelidis, V.G.; Demetriades, G.D. Supercapacitor sizing method for energy-controlled filter-based hybrid energy storage systems. IEEE Trans. Power Electron. 2017, 32, 1626-1637. [CrossRef]

76. Xiao, X.; Yi, H.; Kang, Q.; Nie, J. A two-level energy storage system for wind energy systems. Procedia Environ. Sci. 2012, 12, 130-136. [CrossRef]

77. Abbey, C.; Strunz, K.; Joós, G. A knowledge-based approach for control of two-level energy storage for wind energy systems. IEEE Trans. Energy Convers. 2009, 24, 539-547. [CrossRef] 
78. Babazadeh, H.; Gao, W.; Wang, X. Controller design for a hybrid energy storage system enabling longer battery life in wind turbine generators. In Proceedings of the 43rd North American Power Symposium, Boston, MA, USA, 4-6 August 2011.

79. Li, M.T.; Choi, S.S.; Tseng, K.J.; Yuan, Y.; Sun, C.C. Design of energy storage scheme for the smoothing and dispatch planning of large-scale wind power generation. In Proceedings of the 5th International Conference on Electric Utility Deregulation and Restructuring and Power Technologies (DRPT), Changsha, China, 26-29 November 2015; pp. 2113-2119.

80. Nguyen, C.L.; Lee, H.H. An optimal hybrid supercapacitor and battery energy storage system in wind power application. In Proceedings of the IECON 2015-41st Annual Conference of the IEEE Industrial Electronics Society, Yokohama, Japan, 9-12 November 2015; pp. 3010-3015.

81. Chen, Q.; Chen, X.; Nai, L.; Li, Z.; Liao, Y.; Xu, J. Optimization smoothing control of large-scale wind farm based on hybrid energy storage. In Proceedings of the 2014 International Conference on Power System Technology, Chengdu, China, 20-22 October 2014; pp. 20-22.

82. Wang, G.; Member, S.; Ciobotaru, M.; Agelidis, V.G.; Member, S. Power Smoothing of Large Solar PV Plant Using Hybrid Energy Storage. IEEE Trans. Sustain. Energy 2014, 5, 834-842. [CrossRef]

83. Wang, G.; Ciobotaru, M.; Agelidis, V.G. Power management for improved dispatch of utility-scale PV plants. IEEE Trans. Power Syst. 2016, 31, 2297-2306. [CrossRef]

84. Wee, K.W.; Choi, S.S.; Vilathgamuwa, D.M. Design of a least-cost battery-supercapacitor energy storage system for realizing dispatchable wind power. IEEE Trans. Sustain. Energy 2013, 4, 786-796. [CrossRef]

85. Zhang, Y.; Jiang, Z.; Yu, X. Control strategies for battery supercapacitor hybrid energy storage systems. In Proceedings of the 2008 IEEE Energy 2030 Conference, Atlanta, GA, USA, 17-18 November 2008; pp. 5-10.

86. Mehdi, S.; Achour, B.; Sabrina, A.; Ouchen, S. Implementation of a real-time energy management consisting of a battery and a supercapacitor. In Proceedings of the 2017 5th International Conference on Electrical Engineering-Boumerdes (ICEE-B), Boumerdes, Algeria, 29-31 October 2017; pp. 1-6.

87. Liu, B.; Zhuo, F.; Bao, X. Fuzzy control for hybrid energy storage system based on battery and Ultra-capacitor in Micro-grid. In Proceedings of the Proceedings of the 7th International Power Electronics and Motion Control Conference, Harbin, China, 2-5 June 2012; pp. 778-782.

88. Liu, B.; Zhuo, F.; Bao, X. Control method of the transient compensation process of a hybrid energy storage system based on battery and ultra-capacitor in micro-grid. In Proceedings of the 2012 IEEE International Symposium on Industrial Electronics, Bandung, Indonesia, 23-26 September 2012; pp. 1325-1329.

89. Zhang, R.; Hredzak, B.; Morstyn, T. Cooperative control of distributed heterogeneous energy storage devices with virtual impedance. In Proceedings of the 2017 IEEE Innovative Smart Grid Technologies-Asia (ISGT-Asia), Auckland, New Zealand, 4-7 December 2017; pp. 1-6.

90. Song, Q.; Chen, J. A decentralized energy management strategy for a battery/supercapacitor hybrid energy storage system in autonomous DC microgrid. In Proceedings of the 2018 IEEE 27th International Symposium on Industrial Electronics (ISIE), Cairns, Australia, 13-15 June 2018.

91. Anglani, N.; Oriti, G.; Julian, A.; Catania, V. How to control supercapacitors and to account for the consequent extension of battery lifetime in an isolated AC microgrid. In Proceedings of the International Conference on Environment and Electrical Engineering and 2017 IEEE Industrial and Commercial Power Systems Europe (EEEIC/I\&CPS Europe), Milan, Italy, 6-9 June 2017.

92. Oriti, G.; Julian, A.L.; Anglani, N.; Ingegneria, D.; Hernandez, G.D. Novel hybrid energy storage control for a single phase energy management system in a remote islanded microgrid. In Proceedings of the IEEE Energy Conversion Congress and Exposition (ECCE), Cincinnati, OH, USA, 1-5 October 2017.

93. Ren, Y.; Li, S.; Jiang, L.; Zeng, P. Coordinated control for battery and supercapacitor in hybrid energy storage system in Microgrid. In Proceedings of the 2016 IEEE 8th International Power Electronics and Motion Control Conference (IPEMC-ECCE Asia), Piscataway, NJ, USA, 22-26 May 2016; pp. 2654-2660.

94. Zhao, C.; Yin, H.; Yang, Z.; Ma, C. Equivalent series resistance-based real-time control for a battery-ultracapacitor hybrid system. In Proceedings of the IECON 2015-41st Annual Conference of the IEEE Industrial Electronics Society, Yokohama, Japan, 9-12 November 2015; pp. 1849-1854.

95. Chia, Y.Y.; Lee, L.H.; Shafiabady, N.; Isa, D. A load predictive energy management system for supercapacitor-battery hybrid energy storage system in solar application using the Support Vector Machine. Appl. Energy 2015, 137, 588-602. [CrossRef] 
96. Jia, H.; Mu, Y.; Qi, Y. A statistical model to determine the capacity of battery-supercapacitor hybrid energy storage system in autonomous microgrid. Int. J. Electr. Power Energy Syst. 2014, 54, 516-524. [CrossRef]

97. Akram, U.; Khalid, M.; Shafiq, S. An innovative hybrid wind-solar and battery-supercapacitor microgrid system-Development and optimization. IEEE Access 2017, 5, 25897-25912. [CrossRef]

98. Jun, R.; Kai, W.; Liwei, L. Characteristics analysis of ultracapacitor-battery hybrid energy storage system. In Proceedings of the 2017 Chinese Automation Congress (CAC), Jinan, China, 20-22 October 2017; pp. 5679-5683.

99. Sinha, S.; Sinha, A.K.; Bajpai, P. Solar PV fed standalone DC microgrid with hybrid energy storage system. In Proceedings of the 6th International Conference on Computer Applications in Electrical Engineering-Recent Advances (CERA), Roorkee, India, 5-7 October 2017; pp. 31-36.

100. Tian, G.; Ding, X.; Liu, J. Study of control strategy for hybrid energy storage in wind-photovoltaic hybrid streetlight system. In Proceedings of the 2011 IEEE International Workshop on Open-source Software for Scientific Computation, Beijing, China, 12-14 October 2011; pp. 77-81.

101. Glavin, M.E.; Hurley, W.G. Optimisation of a photovoltaic battery ultracapacitor hybrid energy storage system. Sol. Energy 2012, 86, 3009-3020. [CrossRef]

102. Porru, M.; Serpi, A.; Salimbeni, A.; Damiano, A. An advanced frequency-based energy management of hybrid energy storage systems for microgrids. In Proceedings of the IECON 2017—43rd Annual Conference of the IEEE Industrial Electronics Society, Beijing, China, 29 October-1 November 2017.

103. Tao, W.; Sun, W.; Du, C. Research on super-capacitor and battery hybrid energy storage system applied in micro-grid. In Proceedings of the 2012 International Conference on Control Engineering and Communication Technology, Shenyang, Liaoning, China, 7-9 December 2012; pp. 157-160.

104. Meng, N.; Wang, P.; Wu, H.; Wang, W. Optimal sizing of distributed generations in a connected DC micro-grid with hybrid energy storage system. In Proceedings of the 2015 IEEE Energy Conversion Congress and Exposition (ECCE), Montreal, QC, Canada, 20-24 September 2015.

105. Zhang, Y.Z.Y.; Jiang, Z.J.Z.; Yu, X.Y.X. Small-signal modeling and analysis of battery-supercapacitor hybrid energy storage systems. In Proceedings of the 2009 IEEE Power \& Energy Society General Meeting, Calgary, AB, Canada, 26-30 July 2009; pp. 1-8.

106. Zhang, J.; Ji, L. An effective hybrid energy storage system based on battery-EDLC for distributed generation systems. In Proceedings of the 2010 5th IEEE Conference on Industrial Electronics and Applications, Taichung, Taiwan, 15-17 June 2010; pp. 819-824.

107. Liu, F.; Liu, J.; Zhou, L. A novel control strategy for hybrid energy storage system to relieve battery stress. In Proceedings of the 2nd International Symposium on Power Electronics for Distributed Generation Systems, Hefei, Anhui, China, 16-18 June 2010; pp. 929-934.

108. Kollimalla, S.K.; Mishra, M.K.; Lakshmi, N.N. A new control strategy for interfacing battery supercapacitor storage systems for PV system. In Proceedings of the 2014 IEEE Students' Conference on Electrical, Electronics and Computer Science, Bhopal, India, 1-2 March 2014.

109. Kollimalla, S.K.; Member, S.; Mishra, M.K.; Member, S. Coordinated control and energy management of hybrid energy storage system in PV system. In Proceedings of the 2014 International Conference on Computation of Power, Energy, Information and Communication (ICCPEIC), Melmaruvathur, India, 16-17 April 2014; pp. 363-368.

110. Kollimalla, S.K.; Mishra, M.K.; Narasamma, N.L. Design and analysis of novel control strategy for battery and supercapacitor storage system. IEEE Trans. Sustain. Energy 2014, 5, 1137-1144. [CrossRef]

111. Thakur, A.; Saini, L.M. A voltage and state of charge control technique for battery-supercapacitor hybrid energy storage system for standalone photovoltaic application. In Proceedings of the International Conference on Energy, Power and Environment: Towards Sustainable Growth (ICEPE), Shillong, India, 12-13 June 2015.

112. Manandhar, U.; Ukil, A.; Kollimalla, S.K.; Gooi, H.B. Application of HESS for PV system with modified control strategy. In Proceedings of the 2015 IEEE Innovative Smart Grid Technologies-Asia (ISGT Asia), Bangkok, Thailand, 3-6 November 2015.

113. Manandhar, U.; Wang, B.; Ukil, A.; Beng, G.H.; Tummuru, N.R.; Kollimalla, S.K. A new control approach for PV system with hybrid energy storage system. In Proceedings of the IECON 2017-43rd Annual Conference of the IEEE Industrial Electronics Society, Beijing, China, 29 October-1 November 2017; pp. 2739-2743. 
114. Manandhar, U.; Tummuru, N.R.; Kollimalla, S.K.; Ukil, A.; Beng, G.H.; Chaudhari, K. Validation of faster joint control Strategy for battery- and supercapacitor-based energy storage system. IEEE Trans. Ind. Electron. 2018, 65, 3286-3295. [CrossRef]

115. Kollimalla, S.K.; Mishra, M.K.; Ukil, A.; Gooi, H.B. DC grid voltage regulation using new HESS control strategy. IEEE Trans. Sustain. Energy 2017, 8, 772-781. [CrossRef]

116. Lee, K.; An, B.; Hadi, M.W.; Choi, J.; Song, Y. Optimized control strategy for hybrid energy system. In Proceedings of the 9th International Conference on Power Electronics and ECCE Asia (ICPE-ECCE Asia), Seoul, Korea, 1-5 June 2015.

117. Sharma, R.; Suhag, S. Novel control strategy for hybrid renewable energy-based standalone system. Turk. J. Electr. Eng. Comput. Sci. 2017, 25, 2261-2277. [CrossRef]

118. Hajiaghasi, S.; Salemnia, A.; Hamzeh, M. Hybrid energy storage performance improvement in microgrid application. In Proceedings of the 2018 9th Annual Power Electronics, Drives Systems and Technologies Conference (PEDSTC), Tehran, Iran, 14-15 February 2018; pp. 392-397.

119. Javed, K.; Ashfaq, H.; Singh, R.; Hussain, S.M.; Ustun, T.S. Design and performance analysis of a stand-alone PV system with hybrid energy storage for rural India. Electronics 2019, 8, 952. [CrossRef]

120. Mendis, N.; Muttaqi, K.M.; Perera, S. Active power management of a super capacitor-battery hybrid energy storage system for standalone operation of DFIG based wind turbines. In Proceedings of the 2012 IEEE Industry Applications Society Annual Meeting, Las Vegas, NV, USA, 7-11 October 2012; pp. 1-8.

121. Mendis, N.; Muttaqi, K.M.; Perera, S. Management of battery-supercapacitor hybrid energy storage and synchronous condenser for isolated operation of PMSG based variable-speed wind turbine generating systems. IEEE Trans. Smart Grid 2014, 5, 944-953. [CrossRef]

122. Mendis, N.; Muttaqi, K.M.; Perera, S. Management of low- and high-frequency power components in demand-generation fluctuations of a DFIG-based wind-dominated RAPS system using hybrid energy storage. IEEE Trans. Ind. Appl. 2014, 50, 2258-2268. [CrossRef]

123. Song, Y.D.; Cao, Q.; Du, X.; Karimi, H.R. Control strategy based on wavelet transform and neural network for hybrid power system. J. Appl. Math. 2013. [CrossRef]

124. Zhang, X.; Chen, Y.; Zhou, Y.; Xu, Z.; Huang, Z.; Liu, W. An adaptive energy allocation strategy for battery/supercapacitor hybrid energy storage system. In Proceedings of the 29th Chinese Control and Decision Conference (CCDC), Chongqing, China, 28-30 May 2017.

125. Chong, L.W.; Wong, Y.W.; Rajkumar, R.K.; Isa, D. An adaptive learning control strategy for standalone PV system with battery-supercapacitor hybrid energy storage system. J. Power Sources 2018, 394, 35-49. [CrossRef]

126. Perez, F.; Iovine, A.; Damm, G.; Ribeiro, P. DC microgrid voltage stability by dynamic feedback linearization. In Proceedings of the IEEE International Conference on Industrial Technology (ICIT), Lyon, France, 19-22 Fabruary 2018.

127. Choudar, A.; Boukhetala, D.; Barkat, S.; Brucker, J.M. A local energy management of a hybrid PV-storage based distributed generation for microgrids. Energy Convers. Manag. 2015, 90, 21-33. [CrossRef]

128. Manandhar, U.; Member, S.; Ukil, A.; Member, S.; Gooi, H. A low complexity control and energy management for DC-coupled hybrid microgrid with hybrid energy storage system. In Proceedings of the IEEE Power \& Energy Society General Meeting, Chicago, IL, USA, 16-20 July 2017.

129. Kotra, S.; Mishra, M.K.; Chaithanya, N.P. Design and small signal analysis of DC microgrid with hybrid energy storage system. In Proceedings of the 2017 IEEE PES Asia-Pacific Power and Energy Engineering Conference (APPEEC), Bangalore, India, 8-10 November 2017; pp. 1-6.

130. Zhao, X.; Li, Y.W.; Tian, H.; Wu, X. Energy management strategy of multiple supercapacitors in a DC microgrid using adaptive virtual impedance. IEEE J. Emerg. Sel. Top. Power Electron. 2016, 4, 1174-1185. [CrossRef]

131. Zhang, Y.; Wei Li, Y. Energy management strategy for supercapacitor in droop-controlled DC microgrid using virtual impedance. IEEE Trans. Power Electron. 2017, 32, 2704-2716. [CrossRef]

132. Zhu, Y.; Zhuo, F.; Shi, H. Power management strategy research for a photovoltaic-hybrid energy storage system. In Proceedings of the 2013 IEEE ECCE Asia DownUnder, Melbourne, Australia, 3-6 June 2013; pp. 842-848.

133. Cabrane, Z.; Ouassaid, M.; Maaroufi, M. Analysis and evaluation of battery-supercapacitor hybrid energy storage system for photovoltaic installation. Int. J. Hydrogen Energy 2016, 41, 20897-20907. [CrossRef] 
134. Tummuru, N.R.; Member, S.; Mishra, M.K.; Member, S.; Srinivas, S. Dynamic energy management of hybrid energy storage system with high-gain PV converter. IEEE Trans. Energy Convers. 2015, 30, 150-160. [CrossRef]

135. Zheng, Z.; Wang, X.; Li, Y. A control method for grid-friendly photovoltaic systems with hybrid energy storage units. In Proceedings of the 2011 4th International Conference on Electric Utility Deregulation and Restructuring and Power Technologies (DRPT), Weihai, Shandong, China, 6-9 July 2011; pp. 1437-1440.

136. Han, Y.; Xu, Y.; Li, Y. Research on application of STATCOM/HESS in wind power integrated to the grid. In Proceedings of the IEEE 2nd International Future Energy Electronics Conference (IFEEC), Taipei, Taiwan, 1-4 November 2015.

137. Nikhil, K.; Mishra, M.K. Application of hybrid energy storage system in a grid interactive microgrid environment. In Proceedings of the IECON 2015-41st Annual Conference of the IEEE Industrial Electronics Society, Yokohama, Japan, 9-12 November 2015; pp. 2980-2985.

138. Yallamilli, R.S.; Mishra, M.K. Power management of islanded hybrid microgrid with dual voltage source inverter considering the impact of line impedance. In Proceedings of the 2016 IEEE International Conference on Power Electronics, Drives and Energy Systems (PEDES), Trivandrum, India, 14-17 December 2016; pp. 1-6.

139. Wang, B.; Ye, J.; Manandhar, U.; Ukil, A.; Gooi, H. A DC microgrid integrated dynamic voltage restorer with model predictive control. In Proceedings of the Asian Conference on Energy, Power and Transportation Electrification (ACEPT) 2017, Singapore, 30 October-2 November 2017.

140. Benaouadj, M.; Aboubou, A.; Ayad, M.Y.; Becherif, M. Nonlinear flatness control applied to supercapacitors contribution in hybrid power systems using photovoltaic source and batteries. Energy Procedia 2014, 50, 333-341. [CrossRef]

141. Ismail, N.M.; Mishra, M.K. Control and operation of unified power quality Conditioner with battery-ultracapacitor energy storage system. In Proceedings of the 2014 IEEE International Conference on Power Electronics, Drives and Energy Systems (PEDES), Mumbai, India, 16-19 December 2014; pp. 1-6.

142. Zhang, F.; Yang, Y.; Ji, C.; Wei, W.; Chen, Y.; Meng, C.; Jin, Z.; Zhang, G. Power management strategy research for DC microgrid with hybrid storage system. In Proceedings of the 2015 IEEE First International Conference on DC Microgrids (ICDCM), Atlanta, GA, USA, 24-27 May 2015; pp. 62-68.

143. Kotra, S.; Mishra, M.K. Control algorithm for a PV based hybrid microgrid. In Proceedings of the 2015 Annual IEEE India Conference (INDICON), New Delhi, India, 17-19 December 2015; pp. 4-9.

144. Kotra, S.; Mishra, M.K. Energy management of hybrid microgrid with hybrid energy storage system. In Proceedings of the 2015 International Conference on Renewable Energy Research and Applications (ICRERA), Palermo, Italy, 22-25 November 2015; pp. 856-860.

145. Anzalchi, A.; Pour, M.M.; Sarwat, A. A combinatorial approach for addressing intermittency and providing inertial response in a grid-connected photovoltaic system. In Proceedings of the 2016 IEEE Power and Energy Society General Meeting (PESGM), Boston, MA, USA, 17-21 July 2016; pp. 1-5.

146. Huiyu, M.; Chenyu, Z.; Fei, M.; Yun, Y.; Jianyong, Z. A novel control strategy for hybrid energy system in virtual synchronous generator. In Proceedings of the 2018 13th IEEE Conference on Industrial Electronics and Applications (ICIEA), Wuhan, China, 31 May-2 June 2018; pp. 2244-2249.

147. Zhou, X.; Dong, C.; Fang, J.; Tang, Y. Enhancement of load frequency control by using a hybrid energy storage system. In Proceedings of the 2017 Asian Conference on Energy, Power and Transportation Electrification (ACEPT), Singapore, 30 October-1 November 2017; pp. 1-6.

148. Gu, Y.; Li, W.; He, X. Frequency-coordinating virtual impedance for autonomous power management of DC microgrid. IEEE Trans. Power Electron. 2015, 30, 2328-2337. [CrossRef]

149. Lahyani, A.; Venet, P.; Guermazi, A.; Troudi, A. Battery/supercapacitors combination in uninterruptible power supply (UPS). IEEE Trans. Power Electron. 2013, 28, 1509-1522. [CrossRef]

150. Georgious, R.; Garcia, J.; Garcia, P.; Sumner, M. Analysis of hybrid energy storage systems with DC link fault ride-through capability. In Proceedings of the 2016 IEEE Energy Conversion Congress and Exposition (ECCE), Milwaukee, WI, USA, 18-22 September 2016.

151. Georgious, R.; Garcia, J.; Navarro-Rodriguez, A.; Garcia-Fernandez, P. A study on the control design of non-isolated converter configurations for hybrid energy storage systems. IEEE Trans. Ind. Appl. 2018, 54, 4660-4671. [CrossRef] 
152. Cabrane, Z.; Ouassaid, M.; Nationale, E.; Maaroufi, M. Management and control of storage photovoltaic energy using battery-supercapacitor combination. In Proceedings of the 2014 Second World Conference on Complex Systems (WCCS), Agadir, Morroco, 10-13 November 2014.

153. Dong, B.; Li, Y.; Zheng, Z.; Xu, L. Control strategies of microgrid with Hybrid DC and AC buses. In Proceedings of the 2011 14th European Conference on Power Electronics and Applications, Birmingham, UK, 30 August-1 September 2011; pp. 1-8.

154. Dong, B.; Li, Y.; Zheng, Z. Control strategies of DC-bus voltage in islanded operation of microgrid. In Proceedings of the 2011 4th International Conference on Electric Utility Deregulation and Restructuring and Power Technologies (DRPT), Birmingham, UK, 30 August-1 September 2011; pp. 1671-1674.

155. Zhou, T.; Sun, W. Optimization of battery-supercapacitor hybrid energy storage station in Wind/solar generation system. IEEE Trans. Sustain. Energy 2014, 5, 408-415. [CrossRef]

156. Wang, X.; Yu, D.; Le Blond, S.; Zhao, Z.; Wilson, P. A novel controller of a battery-supercapacitor hybrid energy storage system for domestic applications. Energy Build. 2017, 141, 167-174. [CrossRef]

157. Sanjeev, P.; Prasad Padhy, N.; Agarwal, P. Effective control and energy management of isolated DC microgird. In Proceedings of the IEEE Power \& Energy Society General Meeting, Chicago, IL, USA, 16-20 July 2017.

158. Sinha, S.; Sinha, A.K.; Bajpai, P. Analysis of hybrid storage system in DC microgrid. In Proceedings of the 21st Century Energy Needs-Materials, Systems and Applications (ICTFCEN), Kharagpur, India, 17-19 November 2016.

159. Pan, T.L.; Wan, H.S.; Ji, Z.C. Stand-alone wind power system with battery/supercapacitor hybrid energy storage. Int. J. Sustain. Eng. 2014, 7, 103-110. [CrossRef]

160. Hassan, S.Z.; Kamal, T.; Awais, M. Stand-alone/grid-tied wind power system with battery/supercapacitor hybrid energy storage. In Proceedings of the 2015 International Conference on Emerging Technologies (ICET), Peshawar, Pakistan, 19-20 December 2015; 2015; pp. 1-6.

161. Wu, G.; Ono, Y.; Alishahi, M. Development of a resilient hybrid microgrid with integrated renewable power generations supplying DC and AC loads. In Proceedings of the 2015 IEEE International Telecommunications Energy Conference (INTELEC), Osaka, Japan, 18-22 October 2016.

162. Thale, S.; Agarwal, V. A smart control strategy for the black start of a microgrid based on PV and other auxiliary sources under islanded condition. In Proceedings of the 2011 37th IEEE Photovoltaic Specialists Conference, Seattle, WA, USA, 19-24 June 2011; pp. 002454-002459.

163. Gao, Z.Q.; Xie, Z.J.; Fan, H.; Meng, L. Hybrid energy storage system for GSHP black start. Adv. Mater. Res. 2014, 953-954, 748-751. [CrossRef]

164. Araújo, R.E.; De Castro, R.; Pinto, C.; Melo, P.; Freitas, D. Combined sizing and energy management in EVs with batteries and supercapacitors. IEEE Trans. Veh. Technol. 2014, 63, 3062-3076. [CrossRef]

165. Feng, J.; Qiao, Z.; Weiwen, D.; Jingshan, L. Review of structures and control of battery-supercapacitor hybrid energy storage system for electric vehicles. In Proceedings of the IEEE International Conference on Automation Science and Engineering (CASE), Vancouver, BC, Canada, 22-26 August 2014.

166. Baisden, A.C.; Emadi, A. ADVISOR-based model of a battery and an ultra-capacitor energy source for hybrid electric vehicles. IEEE Trans. Veh. Technol. 2004, 53, 199-205. [CrossRef]

167. Bentley, P.; Stone, D.A.; Schofield, N. The parallel combination of a VRLA cell and supercapacitor for use as a hybrid vehicle peak power buffer. J. Power Sources 2005, 147, 288-294. [CrossRef]

168. Stienecker, A.W.; Stuart, T.; Ashtiani, C. An ultracapacitor circuit for reducing sulfation in lead acid batteries for Mild Hybrid Electric Vehicles. J. Power Sources 2006, 156, 755-762. [CrossRef]

169. Garcia, F.S.; Ferreira, A.A.; Pomilio, J.A. Control strategy for battery-ultracapacitor hybrid energy storage system. In Proceedings of the Twenty-Fourth Annual IEEE Applied Power Electronics Conference and Exposition, Washington, DC, USA, 15-19 February 2009; pp. 826-832.

170. Akar, F.; Tavlasoglu, Y.; Vural, B. An energy management strategy for a concept battery/ultracapacitor electric vehicle with improved battery life. IEEE Trans. Transp. Electrif. 2017, 3, 191-200. [CrossRef]

171. Herrera, V.; Milo, A.; Gaztañaga, H.; Etxeberria-Otadui, I.; Villarreal, I.; Camblong, H. Adaptive energy management strategy and optimal sizing applied on a battery-supercapacitor based tramway. Appl. Energy 2016, 169, 831-845. [CrossRef]

172. Ostadi, A.; Kazerani, M. A comparative analysis of optimal sizing of battery-only, ultracapacitor-only, and battery-ultracapacitor hybrid energy storage systems for a city bus. IEEE Trans. Veh. Technol. 2015, 64, 4449-4460. [CrossRef] 
173. Farzanehfard, H.; Beyragh, D.S.; Adib, E. A bidirectional soft switched ultracapacitor interface circuit for hybrid electric vehicles. Energy Convers. Manag. 2008, 49, 3578-3584. [CrossRef]

174. Pant, Y.V.; Nghiem, T.X.; Mangharam, R. Peak Power Control of Battery and Super-Capacitor Energy Systems in Electric Vehicles; Real Time and Embedded Systems Lab: Philadelphia, PA, USA, 2014.

175. Graber, G.; Galdi, V.; Calderaro, V.; Piccolo, A. Sizing and energy management of on-board hybrid energy storage systems in urban rail transit. In Proceedings of the International Conference on Electrical Systems for Aircraft, Railway, Ship Propulsion and Road Vehicles \& International Transportation Electrification Conference (ESARS-ITEC), Toulouse, France, 2-4 November 2016.

176. Herrera, V.I.; Gaztanaga, H.; Milo, A.; Saez-De-Ibarra, A.; Etxeberria-Otadui, I.; Nieva, T. Optimal energy management of a battery-supercapacitor based light rail vehicle using genetic algorithms. In Proceedings of the 2015 IEEE Energy Conversion Congress and Exposition (ECCE), Montreal, QC, Canada, 20-24 September 2015; pp. 1359-1366.

177. Herrera, V.I.; Gaztañaga, H.; Milo, A.; Saez-De-Ibarra, A.; Etxeberria-Otadui, I.; Nieva, T. Optimal energy management and sizing of a battery-supercapacitor-based light rail vehicle with a multiobjective approach. IEEE Trans. Ind. Appl. 2016, 52, 3367-3377. [CrossRef]

178. Yu, H.; Cheli, F.; Castelli-dezza, F.; Wang, F. Multi-objective optimal sizing and energy management of hybrid energy storage system for electric vehicles. IEEE Trans. Veh. Technol. 2018, 67, 1027-1035.

179. Camara, M.B.; Gualous, H.; Gustin, F.; Berthon, A. Design and new control of DC/DC converters to share energy between supercapacitors and batteries in hybrid vehicles. IEEE Trans. Veh. Technol. 2008, 57, 2721-2735. [CrossRef]

180. Choi, M.-E.; Seo, S.-W. Robust energy management of a battery/supercapacitor Hybrid Energy Storage System in an electric vehicle. In Proceedings of the IEEE International Electric Vehicle Conference, Greenville, SC, USA, 4-8 March 2012; pp. 1-5.

181. Choi, M.E.; Lee, J.S.; Seo, S.W. Real-time optimization for power management systems of a battery/supercapacitor hybrid energy storage system in electric vehicles. IEEE Trans. Veh. Technol. 2014, 63, 3600-3611. [CrossRef]

182. Schaltz, E.; Khaligh, A.; Rasmussen, P.O. Influence of battery/ultracapacitor energy-storage sizing on battery lifetime in a fuel cell hybrid electric vehicle. IEEE Trans. Veh. Technol. 2009, 58, 3882-3891. [CrossRef]

183. Wang, L.; Li, H. Maximum fuel economy-oriented power management design for a fuel cell vehicle using battery and ultracapacitor. IEEE Trans. Ind. Appl. 2010, 46, 1011-1020. [CrossRef]

184. Wong, J.; Idris, N.R.N. A parallel energy-sharing control for fuel cell-battery-ultracapacitor hybrid vehicle. In Proceedings of the IEEE Energy Conversion Congress and Exposition, Phoenix, AR, USA, 16-21 September 2011; pp. 2923-2929.

185. Yoo, H.; Sul, S.K.; Park, Y.; Jeong, J. System integration and power flow management for a series hybrid electric vehicle using super-capacitors and batteries. IEEE Trans. Ind. Appl. 2008, 44, 108-114. [CrossRef]

186. Akli, C.R.; Sareni, B.; Roboam, X.; Jeunesse, A. Integrated optimal design of a hybrid locomotive with multiobjective genetic algorithms. Int. J. Appl. Electromagn. Mech. 2009, 30, 151-162. [CrossRef]

187. Wang, L.; Collins, E.G.; Li, H. Optimal design and real-time control for energy management in electric vehicles. IEEE Trans. Veh. Technol. 2011, 60, 1419-1429. [CrossRef]

188. Song, Z.; Li, J.; Han, X.; Xu, L.; Lu, L.; Ouyang, M.; Hofmann, H. Multi-objective optimization of a semi-active battery/supercapacitor energy storage system for electric vehicles. Appl. Energy 2014, 135, 212-224. [CrossRef]

189. Song, Z.; Hofmann, H.; Li, J.; Han, X.; Zhang, X.; Ouyang, M. A comparison study of different semi-active hybrid energy storage system topologies for electric vehicles. J. Power Sources 2015, 274, 400-411. [CrossRef]

190. Onar, O.C.; Khaligh, A. A novel integrated magnetic structure based DC/DC converter for hybrid battery/ultracapacitor energy storage systems. IEEE Trans. Smart Grid 2012, 3, 296-307. [CrossRef]

191. Lu, S.; Corzine, K.A.; Ferdowsi, M. A new battery/ultracapacitor energy storage system design and its motor drive integration for hybrid electric vehicles. IEEE Trans. Veh. Technol. 2007, 56, 1516-1523. [CrossRef]

192. Kroics, K.; Brazis, V. Supercapacitor based storage system for efficiency improvement of lead-acid powered light electric vehicle. In Proceedings of the 2016 IEEE International Power Electronics and Motion Control Conference (PEMC), Varna, Bulgaria, 25-30 September 2016; pp. 1216-1221.

193. Huang, X.; Curti, J.M.A.; Yoichi, H. Energy management strategy with optimized power interface for the battery supercapacitor hybrid system of Electric Vehicles. In Proceedings of the IECON 2013-39th Annual Conference of the IEEE Industrial Electronics Society, Vienna, Austria, 10-13 November 2013; pp. 4635-4640. 
194. Naseri, F.; Farjah, E.; Ghanbari, T. An efficient regenerative braking system based on battery/supercapacitor for electric, hybrid, and plug-in hybrid electric vehicles with BLDC motor. IEEE. Trans. Veh. Technol. 2017, 66, 3724-3738. [CrossRef]

195. Neenu, M.; Muthukumaran, S. A battery with ultracapacitor hybrid energy storage system in electric vehicles. In Proceedings of the IEEE-International Conference on Advances in Engineering, Science and Management (ICAESM-2012), Nagapattinam, India, 30-31 March 2012; pp. 731-735.

196. Cao, J.; Emadi, A. A new battery/ultracapacitor hybrid energy storage system for electric, hybrid, and plug-in hybrid electric vehicles. IEEE Trans. Power Electron. 2012, 27, 122-132.

197. Shao, L.; Moshirvaziri, M.; Malherbe, C.; Moshirvaziri, A.; Eski, A.; Dallas, S.; Hurzook, F.; Trescases, O. Ultracapacitor/battery hybrid energy storage system with real-time power-mix control validated experimentally in a custom electric vehicle. In Proceedings of the 2015 IEEE Applied Power Electronics Conference and Exposition (APEC), Charlotte, NC, USA, 15-19 March 2015; pp. 1331-1336.

198. Adib, A.; Dhaouadi, R. Modeling and analysis of a regenerative braking system with a battery-supercapacitor energy storage. In Proceedings of the 2017 7th International Conference on Modeling, Simulation, and Applied Optimization (ICMSAO), Sharjah, UAE, 4-6 April 2017.

199. Badawy, M.O.; Sozer, Y. A partial power processing of battery/ultra-Capacitor hybrid energy storage system for electric vehicles. In Proceedings of the 2015 IEEE Applied Power Electronics Conference and Exposition (APEC), Charlotte, NC, USA, 15-19 March 2015; pp. 3162-3168.

200. Badawy, M.O.; Husain, T.; Sozer, Y.; De Abreu-Garcia, J.A. Integrated control of an IPM motor drive and a novel hybrid energy storage system for electric vehicles. IEEE Trans. Ind. Appl. 2017, 53, 5810-5819. [CrossRef]

201. Dixon, J.; Nakashima, I.; Arcos, E.F.; Ortúzar, M. Electric vehicle using a combination of ultracapacitors and ZEBRA battery. IEEE Trans. Ind. Electron. 2010, 57, 943-949. [CrossRef]

202. Montazeri-Gh, M.; Soleymani, M. Investigation of the energy regeneration of active suspension system in hybrid electric vehicles. IEEE Trans. Ind. Electron. 2010, 57, 918-925. [CrossRef]

203. Allègre, A.-L.; Trigui, R.; Bouscayrol, A. Flexible real-time control of a hybrid energy storage system for electric vehicles. IET Electr. Syst. Transp. 2013, 3, 79-85. [CrossRef]

204. Bouscayrol, A.; Trigui, R.; Castaings, A.; Lhomme, W. Practical control schemes of a battery/supercapacitor system for electric vehicle. IET Electr. Syst. Transp. 2016, 6, 20-26.

205. Sierra, A.; Herrera, V.; Gonzaez-Garrido, A.; Milo, A.; Gaztanaga, H.; Camblong, H. Experimental comparison of energy management strategies for a hybrid electric bus in a test-bench. In Proceedings of the 2018 Thirteenth International Conference on Ecological Vehicles and Renewable Energies (EVER), Monte Carlo, Monaco, 10-12 April 2018; pp. 1-9.

206. Shen, J.; Khaligh, A. Design and real-time controller implementation for a battery-ultracapacitor hybrid energy storage system. IEEE Trans. Ind. Inform. 2016, 12, 1910-1918. [CrossRef]

207. Sisakat, S.T.; Barakati, S.M. Fuzzy energy management in electrical vehicles with different hybrid energy storage topologies. In Proceedings of the 2015 4th Iranian Joint Congress on Fuzzy and Intelligent Systems (CFIS), Zahedan, Iran, 9-11 September 2015.

208. Penella, M.T.; Gasulla, M. Runtime extension of low-power wireless sensor nodes using hybrid-storage units. IEEE Trans. Instrum. Meas. 2010, 59, 857-865. [CrossRef]

209. Hu, J.S.; Lu, F.; Zhu, C.; Cheng, C.Y.; Chen, S.L.; Ren, T.J.; Mi, C.C. Hybrid energy storage system of an electric scooter based on wireless power transfer. IEEE Trans. Ind. Inform. 2018, 14, 4169-4178. [CrossRef]

210. Hu, A.P.; You, Y.W.; Chen, F.Y.B.; McCormick, D.; Budgett, D.M. Wireless power supply for ICP devices with hybrid supercapacitor and battery storage. IEEE J. Emerg. Sel. Top. Power Electron. 2016, 4, 273-279. [CrossRef]

(C) 2019 by the author. Licensee MDPI, Basel, Switzerland. This article is an open access article distributed under the terms and conditions of the Creative Commons Attribution (CC BY) license (http://creativecommons.org/licenses/by/4.0/). 